\title{
WestVirginiaUniversity
}

THE RESEARCH REPOSITORY @ WVU

Graduate Theses, Dissertations, and Problem Reports

2009

\section{Understanding emotional pain: A preliminary investigation}

\author{
Ben Weinstein \\ West Virginia University
}

Follow this and additional works at: https://researchrepository.wvu.edu/etd

\section{Recommended Citation}

Weinstein, Ben, "Understanding emotional pain: A preliminary investigation" (2009). Graduate Theses, Dissertations, and Problem Reports. 4549.

https://researchrepository.wvu.edu/etd/4549

This Thesis is protected by copyright and/or related rights. It has been brought to you by the The Research Repository @ WVU with permission from the rights-holder(s). You are free to use this Thesis in any way that is permitted by the copyright and related rights legislation that applies to your use. For other uses you must obtain permission from the rights-holder(s) directly, unless additional rights are indicated by a Creative Commons license in the record and/ or on the work itself. This Thesis has been accepted for inclusion in WVU Graduate Theses, Dissertations, and Problem Reports collection by an authorized administrator of The Research Repository @ WVU. For more information, please contact researchrepository@mail.wvu.edu. 
Understanding Emotional Pain: A Preliminary Investigation

\author{
Ben Weinstein
}

Thesis submitted to the Eberly College of Arts and Sciences at West Virginia University in Partial Fulfillment of Requirements for the degree of Master of Science

in Psychology

Daniel W. McNeil, Ph.D., Chair

Kevin Larkin, Ph.D.

B. Kent Parker, Ph.D.

Department of Psychology

Morgantown, WV

2009

Keywords: Emotional Pain, Physical Pain, Trauma, Depression 


\section{ABSTRACT \\ Understanding Emotional Pain: A Preliminary Investigation}

\section{Ben Weinstein}

The purpose of this study was to examine the construct of emotional pain, as well as its relation to other affective and sensory states. There were 250 undergraduates who signed into an online data collection mechanism and were randomly assigned to five groups in which they wrote a vignette about a personal experience. Participants who indicated they previously had experienced the situation wrote a personal account about an emotionally painful, physically painful, traumatic, depressing, or joyful situation. Additionally, participants completed questionnaires to describe emotional state, pain descriptions, anxiety sensitivity and possible symptoms of depression and posttraumatic stress disorder associated with their past experience. The emotional pain group was found to have significantly higher negative affective ratings and affective pain descriptions than the physical pain or joy groups. Participants reporting physical pain conveyed the most intense overall evaluations of the pain experience and sensory pain descriptions. Content analysis revealed that ratings of the correspondence between situations participants were assigned to write about significantly reflected the written content, with some variability in differentiating emotional pain from depression and trauma. 


\section{Acknowledgements}

To my parents, Phil and Barbara, I want to thank sincerely for their love and guidance.

I would like to thank my advisor, my committee chair, and my friend Dan McNeil, who has been an invaluable asset and has offered copious amounts of advice, direction, and moral support over the past two and a half years.

I also would like to thank Kent Parker and Kevin Larkin for serving on my committee, and offering their time and advice.

Additionally, I want to thank all those in the Anxiety, Psychophysiology, and Pain Research Laboratory in the Department of psychology at West Virginia University who helped with my data ratings: Brandi Cheetham, Suzan Clemens, Audrey File, Brandon Kyle, Dan McNeil, Tiffany Ngan, Grant Schulman, and Vincent Sullivano. 
Table of Contents

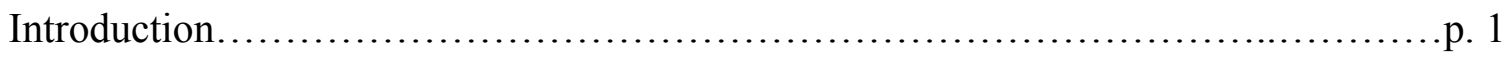

The Experience of Physical Pain ..................................... 1

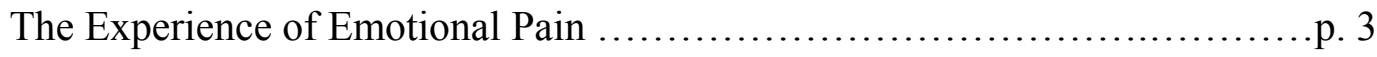

Pain Definitions and Pain Words in Lay Language..........................p. 7

Shared Neurological Correlates of Physical and Emotional Pain ...............p. 9

Relation to Posttraumatic Stress Disorder .............................p. 11

The Role of Social Interaction in Emotional Pain ........................p. 12

Evolutionary Support for Emotional Pain ............................p. 13

Statement of the Problem ..........................................p. 14

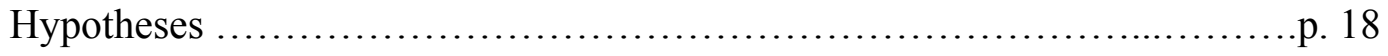

Method ............................................................. 19

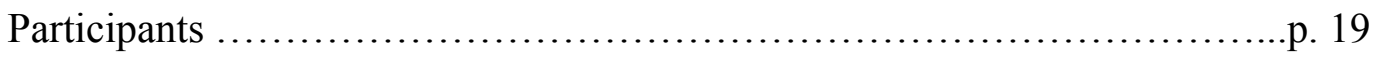

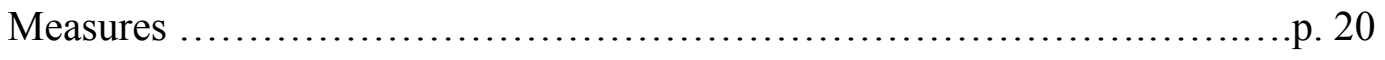

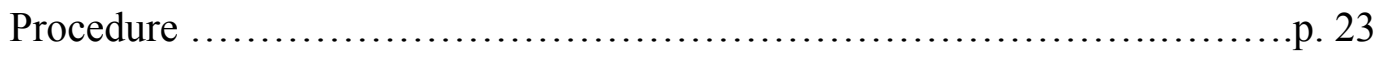

Content Analysis of Emotional Pain Vignettes ...........................p. 25

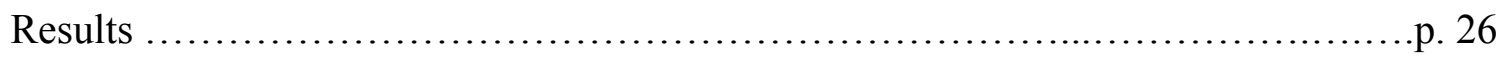

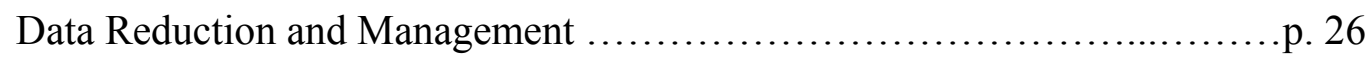

Demographics, Background Characteristics, and Equivalence of Groups .....p. 27

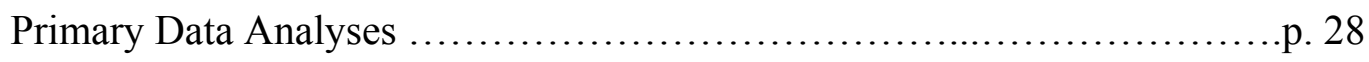

Exploratory Data Analyses ........................................p. 31

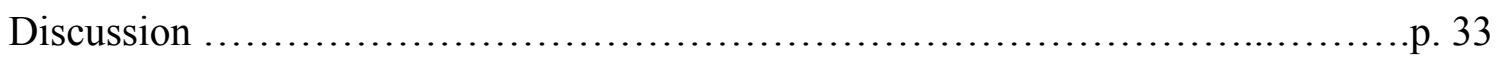

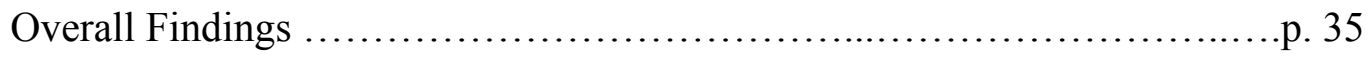




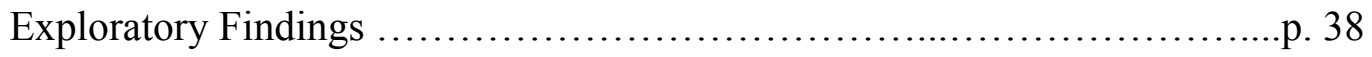

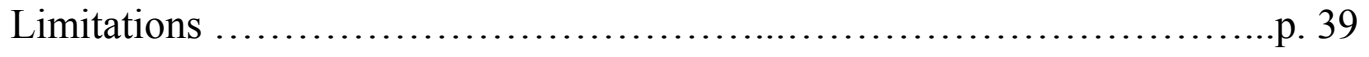

Future Research ................................................p. 36

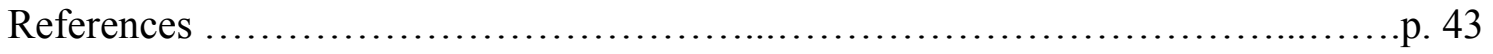

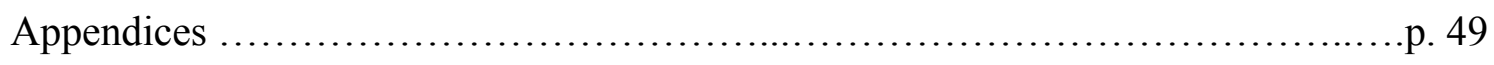

Tables ........................................................................... 59 
Understanding Emotional Pain: A Preliminary Investigation

"I will never fully recover from the pain of child death. Wounds scab over;

incisions heal; broken bones mend; but a heart shattered from child death cannot easily, if ever, be put back together again" (Sheehan, 2006, p. 1).

This quote exemplifies how negative affect and aversive experiences frequently are communicated in terms of physical pain, even when no physical experience of pain is present. Metaphors such as "broken hearted" or "hurt feelings" often are used to describe intense experiences of "pain" felt in response to personal tragedy and loss. This phenomenon is referred to here as emotional pain and is distinguished by self reports of pain occurring with a strong affective component in the absence of any direct physical stimulus. Clinicians frequently hear reports of emotional pain caused by various experiences. While it is apparent that emotional pain is felt physically and not just figuratively, there is not a clear understanding of what causes or constitutes emotional pain.

\section{The Experience of Physical Pain}

The experience of pain is responsible for warning the body of aversive or potentially harmful situations. Pain commonly is associated with the distinction of physical sensation through intensity, quality, duration and location (Price, 1999). Pain sensation is collected and transduced from receptors called "nociceptors," which present a number of different structures in the central nervous system with information of tissue damage along a number of nociceptive pathways (Willis \& Westlund, 1997). It is important to note that the nociceptors do not produce the experience of pain, but merely collect the initial information. In fact, pain can be experienced in the absence of 
nociceptive stimulation (Price). Early theories of pain focused on pain purely as a sensation that is felt in response to direct physical stimuli and largely ignored the complicated neurogenic and psychological factors that affect pain perception (Gatchel, 1999; Melzack, 1993). Pain that was not due to direct physical causes was called "psychogenic" and was considered made-up or "in the patients head" (Gatchel, p. 7). Today, it is well accepted that psychogenic pain is not experienced any differently than pain entirely due to tissue damage (Gatchel). Pain is not just the sum of input of tissue damage sent from nociceptors. Evaluating pain as coming from a specific source is not a requirement of pain sensation. Price points out that pain can be "simply there, inside us, with no reference to anything beyond themselves" (p. 3).

It is important to note that the sensation of pain presented by nociceptive stimuli is not solely responsible for the unpleasantness of pain. The sensation, paired with the unpleasantness of the emotional response, combine to form the aversive properties of pain (Price, 1999; Turk \& Flor, 1999). The pain system is composed of two separate, but highly interactive components: pain sensation and pain affect (Price; Rainville, 2002). The emotional experience of pain is used as a signal of an aversive state that motivates change of behavior such as avoidance or escape, to stop undesirable stimulation (Macdonald \& Leary, 2005). Emotional reactions often reflect the appraisal of whether or not a situation is positive or negative, which can lead to behavioral responses of avoidance or approach (Price). The expressive behaviors of emotions often are used to communicate information to others and to help change environmental situations in ways that are usually adaptive (Plutchik, 2003). This affective experience includes a wide array of emotions such as fear, anger, frustration, anxiety, hopelessness, and depression. These 
negative emotional feelings, which are integral components of pain, are in response to the disagreeable qualities and harmful implications of pain sensation and lead to the desire to stop the pain sensation and emotional feeling (Macdonald \& Leary). Price identifies the unpleasant emotional aspect of pain as being influenced by an individual's goals and desires to cope with and reduce pain, and the expectations related to these desires. Additionally, the perception of control over pain can lower reports of pain, and increase pain tolerance (Arntz \& Schmidt, 1989). As time progresses, these factors can change the way pain is perceived. The emotional unpleasantness of pain can exhibit much variation depending on environmental or psychological processes (Price).

\section{The Experience of Emotional Pain}

The idea that the experience of physical injury uses the same or similar neural mechanisms as the affective component of pain may seem strange because of the differences inherent in the way the sensory modalities are encountered. On the surface, the two dimensions of pain seem relatively different. Pain sensation is conveyed through tangible physical contact, while affective experiences involve more of an abstract and subjective cognitive appraisal that can use symbolic meanings of words, emotions, expectations and desires. The two separate dimensions of affective and sensory experiences of pain have been shown to be reliably different in the appraisal of different types of pain. Rainville et al. (1997) established that differences in duration and expectation of pain led to a significant disparity in the sensory and affective appraisals of nociceptive stimulus intensity. Rainville's work highlights the ability of the affective and sensory components of pain to function independently of each other. 
The separation of the two components of pain sensation and pain affect make it possible for painful sensations to be experienced without a direct physical stimulus by stimulating the neural components pertaining to pain affect (Rainville, 2002).

Experiencing pain from a direct physical stimulus is a common occurrence, but it is likely that many people have also experienced painful stimulation when there was not a tangible physical stimuli present to elicit the pain. Traumatic situations and events have been shown to elicit very powerful feelings of pain (Bolger, 1999; Eisenberger, Lieberman, \& Williams, 2003; Greenberg \& Bolger, 2001; Macdonald \& Leary, 2005). This phenomenon is known as emotional pain and is similar to physical pain, in that it triggers painful sensations and emotional responses, which may serve to assess and respond to causes of our aversive reactions.

At this point, it is useful to clarify other similar terms that are used to describe the pain that is experienced in response to traumatic experiences. There are many different models and conceptualizations of the phenomenon of experiencing pain not caused by a physical sensation. For example, the term "mental pain" often is used interchangeably with emotional pain (Orbach, 2003; Orbach, Mikulincer, Sirota \& Schectman-Gilboa, 2003). There are several different models of emotional pain. "Psychic pain" is a commonly used term to refer to pain that is experienced without a physical stimulus. Psychic pain is defined by the APA Dictionary of Psychology as "intolerable pain caused by intense psychological suffering (rather than organic dysfunction). At its extreme, prolonged psychic pain can lead to suicide attempts" (VandenBos, 2007, p. 748). The term psychic pain puts emphasis on the distress caused by the experience of pain, especially with respect to it as a contributing factor of suicidal behavior. In fact, messages 
connoting emotional pain are very common in suicide notes (Mee, Bunney, Reist, Potkin, \& Bunney, 2006).

The term "psychache" is a theoretical construct created by Shneidman (1999) as a way of explaining suicidal behavior. Psychache is based on a phenomenological model, and refers to psychological pain as the result of frustration from important unmet needs (e.g., to have control, to feel secure, to be loved) that are expressed through a variety of negative emotions such as shame, guilt, defeat, grief, humiliation, hopelessness, and anger (Shneidman). Therefore, when needs are unmet, multiple negative emotions generalize to form psychache, which is a form of emotional perturbation. When psychache becomes unbearable, an individual must resort to suicide in order to escape the emotional pain. Thus, the psychache model of emotional pain outlined by Shneidman should be operationalized by the level of frustration of unmet needs and emotional perturbation. Baumeister (1990) has a similar approach to the psychache model, in that suicide is a result of attempting to end aversive feelings that are caused by failures and disappointments that are attributed to oneself. Thus, Baumeister's model of the emotional pain can be operationally measured by the degree of self-disappointment and negativity. While Baumeister's and Shneidman's definitions are interesting, they appear to have a relatively limited scope, and are purely theoretically based.

Orbach et al. developed a scale relating to the experience of mental pain (Orbach \& Mikulincer Mental Pain Scale; OMMP) from a content analysis of interviews and written narratives from individuals reporting mental pain (Orbach, 2003; Orbach et al., 2003). Based on their content analysis, Orbach found that mental pain consists of a perception of negative changes in ones' self, feeling abandoned, and negative feelings 
from a sense of an irreversible loss of oneself or others. Orbach et al. define mental pain as "a wide range of subjective experiences characterized as an awareness of negative changes in the self and its functions accompanied by negative feelings" (p. 224). Thus, the changes in the self and the function of the self are related to a wide range of negative emotions (Orbach et al.). Since the conceptualization of mental pain has such a strong emotional component, this paper will refer to this phenomenon as emotional pain. The construct of emotional pain goes beyond emotional distress, however, and should be viewed as its own distinct entity. Orbach et al. found that mental pain, depression, and anxiety are all significantly related, but do not completely overlap. In fact, Orbach's OMMP scale distinguished between suicidal and non-suicidal individuals in a sample of inpatient adolescents, and correlated significantly with the Multi-Attitude Suicide Tendency Scale for adolescents (MAST, Orbach et al., 1991). The OMMP also had a significant, moderate positive correlation with depression and anxiety as measured by the Cognition Checklist (CCL), supporting the notion that emotional pain, depression, and anxiety are related, but distinguishable constructs (Orbach).

Based on the qualitative analysis of interviews with individuals reporting emotional pain based in grounded theory, Bolger (1999) created a model depicting the experience of emotional pain. Bolger defines emotional pain as a sense of alarm, a loss of control and "the awareness of a feeling of brokenness" resulting from a traumatic event (p. 357). The characteristics of brokenness involve: feeling wounded, a disconnection from an important relationship, and a loss of self-identity which includes a new awareness of negative features of themselves. 
Interestingly, all of the above mentioned models of emotional pain have some similar features in common that were suggested or implied. An abundance of negative emotions, a sense of hopelessness, and loss of identity seem to be consistent themes across the emotional pain models. Additionally, the role of emotional pain in suicidal behavior appears to be a recurring subject, and a pertinent topic for future clinical research. Commonalities were also found in the visceral and spatial descriptors used to describe emotional pain in Bolger's study. Pain in the head, stomach, and heart, as well as feelings of a weight, emptiness, a vacuum, or a physical wound all were used to describe emotional pain experiences (Bolger). As Orbach et al. (2003) pointed out, both alarm and woundedness are integral components of the physical pain response. Physical pain prompts individuals to avoid circumstances which may lead to similar situations of harm, just as emotional pain causes individuals to avoid repeating circumstances that once elicited distress. The threat defense response for emotional pain is the same unpleasant emotional state as for physical pain. For the purposes of this study, emotional pain can be defined as painful sensations experienced in the absence of a direct physical stimuli that are experienced in response to traumatic or emotionally unpleasant experiences. Thus, feelings of emotional pain can result from unpleasant traumatic and emotional experiences, but not as the result of internally painful events such as headaches, that may be caused by tension, eye strain, or dehydration.

\section{Pain Definitions and Pain Words in Lay Language}

The American Psychological Association Dictionary of Psychology refers to pain as "an unpleasant emotional as well as sensory experience. Pain may also be a feeling of severe distress and suffering resulting from acute anxiety, loss of a loved one, or other 
psychological factors" (VandenBos, 2007, p. 664). This conceptualization recognizes both the emotional and sensory aspects of pain, and acknowledges that the experience of pain can result from traumatic experiences. It is interesting to note that the suffering from acute anxiety can result in the experience of pain. There is no one standard conceptualization of pain, however, and some definitions stress certain characteristics more than others. Another popular pain definition is "an unpleasant sensory and emotional experience associated with actual or potential tissue damage, or described in terms of such damage" (International Association for the Study of Pain Task Force on Taxonomy, 1994, p. 211). This definition also highlights the experience of pain in response to emotional or physical damage, and the verbal expression of pain in terms of this damage. One of the most salient links between emotional and physical pain can be found in the overlap of terms used to describe them. Philosophers, poets, and musicians of many cultures commonly refer to the phenomenon of emotional pain using phrases such as "broken hearted" or feeling emotionally "wounded" or "scarred." These phrases that connote physically painful experiences are commonly heard in the context of referring to traumatic or distressing events in one's life. What is interesting is that in many cases these colloquialisms are used in the absence of any physical pain or tangible threat to one's health. The use of words and expressions to describe emotional pain using physical pain imagery is a common occurrence in lay language. Even awkward social events often are referred to as "painful" or "excruciating." Thus, social pain (a subcomponent of emotional pain) is frequently described using physical pain terms. Unlike many other emotional states, the English language does not have any directly synonymous term to refer to hurt feelings. The only way that hurt feelings can be 
conveyed in the English language is by using physical pain terms (Macdonald \& Leary, 2005). In fact, the linguistic connection between social and physical pain exists in over fourteen languages in diverse cultures (Eisenberger \& Lieberman, 2004; Macdonald \& Leary). This overlap between physical and emotional pain, however, does not end with linguistics, as is demonstrated by findings in the recent neurological and neuroimaging literature.

\section{Shared Neurological Correlates of Physical and Emotional Pain}

It has been well documented that affective and sensation components of physical pain share similar neurological pathways (Price, 1999). Recently the connection between the neurological components of emotional pain (in the absence of physical stimulation) and the components of physical pain has been demonstrated in the neurological literature. An overlap has been discovered in brain areas used to process both emotional and physical pain. The majority of the evidence demonstrating a neurological overlap in the affective and physical pain experience in humans involves anterior cingulate cortex (ACC) and anterior insula (AI) activation (Eisenberger, Jarcho, Lieberman, \& Naliboff, 2006; Eisenberger et al., 2003; Rainville, 2002). The intensification of unpleasant physical stimulation alters activity in the ACC and AI regions which relate to perceived pain aversiveness, whereas the somatosensory cortices tend to be involved in the sensory domain of pain experience which determine location, duration and intensity (Rainville).

Patients suffering intractable chronic pain may undergo a cingulotomy, which is a lesioning of the ACC that causes patients to report that they still feel pain, but that it is not distressing anymore (Eisenberger \& Lieberman, 2004). The ability to feel pain in the absence of distress emphasizes the emotionally unpleasant role mediated by the ACC instead of the physical component of pain. The dorsal anterior cingulate cortex (dACC), 
which is closely associated with the felt unpleasantness of physical pain, was found to be activated in response to carefully induced implicit and explicit social rejection that involved no physical pain (Eisenberger et al., 2003; Eisenberger \& Lieberman, 2004). The activation of the ACC through induced social rejection demonstrates that reactions to physical and social pain must use many of the same neurological components.

Eisenberger, Jarcho, Lieberman, and Naliboff (2006) performed an experiment that found greater reports of social distress from induced social rejection to be associated with increased pain unpleasantness in response to pain stimuli, which supports the notion that social distress and pain distress share similar neural networks. Rainville et al. (1997) found the ACC to be directly involved in the encoding of pain affect, specifically encoding pain unpleasantness. In their 1997 experiment, Rainville et al. demonstrated that hypnotic suggestions, specifically directed at the emotional dimension of pain, produce a specific modulation of ACC activity to alter pain unpleasantness, but did not alter the somatosensory cortices implicated in pain sensation and discrimination.

The unpleasantness of pain affect plays a large role in the learned response of avoiding future causes of emotional pain. Thus the ACC's role of creating emotionally unpleasant neural responses appears to be associated with aversive emotional learning. In an interesting study by Najib et al. (2004), subjects were asked to recall a sad thought about their recently lost loved one (which induced acute grief), and found that subjects showed brain activity changes in the ACC using functional magnetic resonance imaging (fMRI). Additionally, a similar study examining acute grief found that the ACC was activated by women viewing photographs of recently deceased relatives versus photographs of strangers, indicating an overlap in patterns of negative emotion and pain 
activation (Gündel, O’Connor, Littrell, Fort, \& Lane, 2003). Although grief and emotional pain are not equivalent, they are closely related constructs (Thornhill \& Thornhill, 1989), and share similar neural networks with physical pain. What is not well understood is how other similar aversive experiences differ from, or overlap with emotional pain.

\section{Relation to Posttraumatic Stress Disorder}

By definition, traumatic events evoke intense fear, helplessness, or horror (American Psychiatric Association, 1994). According to epidemiological research, over two-thirds of American adults have experienced one or more traumatic events in their lives (Kubany, Leisen, \& Kaplan, 2000). Some of the long-term symptoms of trauma are emotional distress, somatization, cognitive distortions, and dissociation (Elliott, 1997).

Other symptoms of trauma include the symptoms of posttraumatic stress disorder, which consist of experiencing traumatic circumstances, anxious arousal, numbing of general responsiveness, recurrent intrusive experience of the traumatic circumstance(s), avoidance of stimuli associated with the traumatic circumstance(s), and significant distress or impairment (American Psychiatric Association, 1994). Individuals with PTSD often experience negative thoughts that are related to the traumatic event or environment, and negative thoughts about themselves or their own reactions (Beck, 2004).

Consequently, these negative cognitions combine to produce a sense of threat which increases PTSD symptomatology (Beck). PTSD and emotional pain are similar in that they are both aversive reactions to traumatic experiences that include negative cognitions. PTSD and emotional pain, however, are not equivalent, and should be viewed as separate constructs that are related to experiencing a traumatic event (Orbach et al., 2003). The 
most obvious difference between the two being that the diagnosis of PTSD does not require the experience of pain. Another difference between the experience of PTSD and emotional pain may be in the type of trauma related thoughts about the external environment. Self blame and internal attributions in response to emotionally painful experiences are consequences of these events that are supported by much of the emotional pain literature (Baumeister, 1990; Bolger, 1999; Orbach, 2003; Shneidman, 1999). Negative thoughts and appraisals about the self are likely to occur in both emotionally painful responses and in the trauma-related cognitive responses of PTSD (Beck et al., 2004). Negative thoughts and appraisals about the environment which create a sense of threat (i.e., dangerousness of the world) are supported as major features of the development of PTSD, but not emotional pain (Baumeister, 1990; Beck et al., 2004). Interestingly, interpersonal interactions connoting relational devaluation are perceived as threatening, as well as emotionally painful (Eisenberger, 2006).

\section{The Role of Social Interaction in Emotional Pain}

Emotional pain involves an array of private experiences which create negative feelings and an awareness of negative changes of the self (Orbach et al., 2003). Many of the causes of emotional pain stem from social events such as interpersonal loss. Social pain is the interpersonal component of emotional pain, and it is characterized as an emotional reaction to the perception of being excluded from desired relationships or being devalued by desired relationship partners or groups (Macdonald \& Leary, 2005). The work of Leary and Springer (1998) used autobiographical narratives to thoroughly examine the experience of "hurt feelings," which involved pain that was felt in response to social events. It was found that an important aspect of the aversive experience of social 
pain involved the perception of relational devaluation, which was found to be a strong predictor of situations that caused hurt feelings (Leary \& Springer, 1998).

Hurt feelings are the acute feelings of distress which are felt in response to relational devaluation (Leary \& Springer, 2001). Reactions that cause emotional pain should occur only when significant relational devaluation is perceived, and there is a desire to preserve a relationship with the devaluating party. Recent research has demonstrated an overlap between the neural substrates of pain distress and social distress pain (Eisenberger et al., 2003; Eisenberger \& Lieberman, 2004; Panksepp, 2003). The relation between pain and social learning can be seen when the importance of interpersonal relationships between humans is examined. From an early age, humans learn that social isolation and pain are positively correlated together. A child learns that discomfort can be alleviated by contact with caregivers and that the aversive pains of hunger and gas are not relieved until their attachment figure is in contact with them again (Macdonald \& Leary, 2005). Thus, the pain that is felt in response to isolation provides a strong learning mechanism. In fact, isolation is so aversive that victims of social ostracism report they would have preferred to be beaten over ostracized, and that their experiences have scarred them for life (Willis, 1997).

\section{Evolutionary Support for Emotional Pain}

Human beings are social creatures, and historically have needed social support to survive. Being isolated from others decreases the likelihood of survival and reproduction. Thus, a salient mechanism for detecting and recruiting attention to threats to social attachment would be of great value. It is theorized that humans have evolved to suffer emotional pain in relation to conditions that would have historically reduced our ability to 
survive or reproduce (Thornhill \& Thornhill, 1989). One way in which emotional pain may work is by focusing attention on sources of possible social isolation, which can be corrected in the future. Thus, emotional pain, instead of only being an incidental pathological condition, serves the adaptive function of informing individuals of conditions that historically may have adversely affected their survival. Behaviors that lead to social isolation are punished by the aversive feelings of emotional pain, which increases the learned avoidance of future socially-isolating behaviors, and minimizes future isolating circumstances (Thornhill \& Thornhill). Emotional pain can provide a swift and enduring reaction via painful sensations to remind the individual to behave in ways that maximize one's ability to survive or reproduce. It recently has been theorized that early humans emotional pain "piggybacked" onto the physical pain system in order to decrease social isolation and increase inclusive fitness by using social pain as punishment (Eisenberger et al., 2003; Eisenberger \& Lieberman, 2004; Macdonald \& Leary, 2005; Panksepp, 2003). Thus, our pain responding may have adapted to force assessment of our social environment, with the aversive emotional pain experience serving as a salient and deliberate response to actual or potential social problems (Thornhill \& Thornhill). Those early humans who developed emotional pain systems to regulate their social interactions and encourage interdependence would have had an evolutionary advantage, and would be more likely to pass on their genes as humans developed more organized social structures (Macdonald \& Leary; Thornhill \& Thornhill).

\section{Statement of the Problem}

The pain literature supports the idea of both affective and sensory pain components. A growing amount of literature acknowledges that the affective component 
of pain can be present independent of the sensory component, and that the affective pain component uses some of the same neurological pathways in the absence of direct pain stimulation. Thus, there is increasing evidence that the phenomenon of emotional pain is real, and exists as its own independent entity. Nevertheless, relatively little research has been done to look at emotional pain as a construct. Research on the prevalence, causes, consequences, and interpretations of emotional pain would benefit from researching some important issues.

First, of the sparse literature that led to the development of emotional pain models, the majority is purely theoretically based, and has not used empirical methods to study the experience of emotional pain. Additionally, many of the studies examining emotional pain offer vivid descriptions of the experience of emotional pain, but do not provide an operationalized assessment. Due to the limited exploratory research in the field of emotional pain, replication of the systematic assessment by Orbach et al. (2003) is needed to increase confidence in their findings that emotional pain consists of negative feelings and perceptions of self blame, stemming from an irreversible loss of oneself or others. More research needs to be done on the wide scope of components involved in the experience of emotional pain.

Second, it is well known that emotional pain produces negative emotional states of varying intensity (Robinson \& Riley, 1999). Emotional pain has been shown to involve painful sensations and aversive emotional feelings in response to traumatic stimuli (Bolger, 1999; Eisenberger, Lieberman, \& Williams, 2003; Greenberg \& Bolger, 2001; Macdonald \& Leary, 2005). To explore the phenomenology of emotional pain, it is imperative to know what emotional state is associated with the occurrence of emotional 
pain, and how severely the emotional state is experienced. Retrospective autobiographical narratives have previously been used to investigate the content of subjective emotional pain responses (referred to as "hurt feelings") from interpersonal victimization (Macdonald \& Leary). It was found that victims' hurt feelings were strongly correlated with perceived relational devaluation, which was characterized by undifferentiated negative affect (Macdonald \& Leary). Research with a number of different populations has shown that participants are willing to disclose an exceptional variety and depth of traumatic experiences including deaths, sexual and physical abuse, failures, and lost loves (Pennebaker, 1997). Additionally, writing about emotional topics has been shown to have certain beneficial qualities. Multiple studies have found an increase in improved health outcomes in participants assigned to write about emotional topics, rather than those who were assigned to write about superficial topics (such as use of time) as a control (Pennebaker; Smyth, 1998). Health outcomes were improved in terms of reported physical health, psychological well being, physiological functioning, and general functioning (Smyth). Obtaining the self report of negative affect from participants when their emotional pain was felt should provide insight into the experience of emotional pain and how it relates to certain emotional states.

Third, as was discussed previously, there is wide variety of the descriptions of the pain that emotional pain victims report. Even though Bolger's (1999) study found commonalities in the visceral and spatial descriptors used to describe emotional pain, there was still much variability in reports. The physical descriptions of emotional pain should be investigated to better determine how emotional pain is typically experienced and how severely it is experienced. 
Finally, emotional pain is a subjective state that may share common features with other aversive emotional states. Examining the relations and overlap of symptoms and situations that emotional pain shares with similar constructs could increase the usefulness of the emotional pain construct. Theoretical models of emotional pain attempt to distinguish it from other constructs associated with traumatic experiences and negative changes such as depression, anxiety, and PTSD (Baumeister, 1990; Bolger 1999; Shneidman, 1999). Shneidman stresses the role of emotional pain in suicidal behavior, implying suicide is directly linked to emotional pain. The ability for clinicians to distinguish emotional pain from the negative features of emotional distress, or the related states of depression and PTSD, could serve an important role in research and prevention of suicidal behavior. The work of Orbach et al. (2003) has been the only data driven research to distinguish emotional pain from the related mental states of depression and anxiety. Further research aimed at distinguishing emotional pain from depression should be conducted to increase confidence that emotional pain is an independent experiential entity. Additionally, it remains necessary to differentiate the experience of PTSD from emotional pain, since both are closely related to traumatic experiences.

This study attempted to compare experiences of emotional pain to experiences of physical pain, trauma, depression, and joy (as a control) to support the conceptualization of emotional pain as an independent entity. Separate groups were utilized where individuals were assigned to write about personal autobiographical experiences of emotional pain, physical pain, trauma, depression, and joy as a method of comparison of emotional pain with related experiences. Additionally, participants completed online questionnaires to describe the emotional state, pain descriptions, anxiety sensitivity and 
possible symptoms of depression and posttraumatic stress disorder associated with their past experience.

\section{Hypotheses}

The current study of emotional pain, physical pain, trauma, depression, and joy had four major hypotheses.

First, it was predicted that the experience of emotional pain would be associated with an increased self report of negative affect, with participants reporting emotionally painful situations conveying greater intensity of negative affect than any other group, as measured by the Positive and Negative Affect Schedule (PANAS). Participants reporting joyful situations were expected to endorse less negative affect and more positive affect than the other four groups.

Second, it was predicted that the experience of an emotionally painful situation, a physically painful situation, a traumatic situation, a depressing situation, or a joyful situation would have different effects on the quality and intensity of participants' reported pain experience, as measured by the Short-Form McGill Pain Questionnaire (SF-MPQ). Specifically, participants instructed to report an experience of emotional pain were expected to endorse more intense affective descriptions of their pain, while participants reporting a physically painful experience would use more intense sensory descriptions. Both the groups reporting an emotionally painful situation and a physically painful situation were expected to rate more intense overall pain experiences than the other three groups.

Third, it was predicted that the experience of an emotionally painful situation, a physically painful situation, a traumatic situation, a depressing situation, or a joyful 
situation would have different effects on the degree of reported trauma-related thoughts and beliefs, as measured by the Posttraumatic Cognitions Inventory (PTCI). Specifically, participants who reported trauma-related thoughts were expected to meet more posttraumatic stress disorder diagnostic criteria than participants who reported an emotionally painful situation on the PCTI (Although diagnostic criteria were examined, no clinical diagnoses were made). More precisely, participants who reported a traumatic situation or a depressed situation were expected to endorse a greater number of items on the subscale of the PTCI regarding negative cognitions about the world than any other group. Those who experienced either a traumatic situation or an emotionally painful situation were expected to have higher PCTI scores than the other three groups. No significant differences on PCTI scores were expected in the groups describing a physically painful situation or a depressing situation. Those who experienced a joyful situation were expected to have lower PCTI scores on all subscales than any other group.

Fourth, it was predicted that the ratings of the events involved in participants' written narratives would differ across groups (an emotionally painful situation, a physically painful situation, a traumatic situation, a depressing situation, or a joyful situation). Ratings were conducted by trained research assistants who rated the narratives on how much every narrative corresponded to each of the five groups.

\section{Method}

\section{Participants}

Based on the research of Leary and Springer (1998) and Orbach et al. (2003), and calculations outlined by Keppel and Wickens (2004), an effect size of $\omega^{2} \approx .15$ was expected in the present study. Keppel and Wickens characterize effect sizes of $\omega^{2}=.15$ 
or greater as a large effect. The present study involved a total of 583 undergraduate student participants who took part in this study until useable data from 250 participants were collected. Any students who were under the age of 18 years were excluded from this study. Participants who indicated that they had never experienced the situation they were assigned to write about for their group were assigned to a default group that wrote about a joyful experience, these data were separate from the other joy group, and were not used in the present study. All participants received extra credit for participation. All eligible participants were presented with a brief explanation of the study, and agreed to an informed consent text. After the experiment ended, participants were thanked for their participation, and were presented with a list of mental health resources. (See Appendix H for a copy of the mental health resources.)

\section{Measures}

Positive and Negative Affect Schedule. Participants' affect were measured using the Positive and Negative Affect Schedule (PANAS; Watson \& Clark, 1988). The PANAS consists of 10 items representing positive affect, and 10 items representing negative affect. Participants rated items on a scale of 1 (very slightly or not at all) to 5 (extremely). The PANAS demonstrates high internal consistency $(\alpha=.84-.90)$, and excellent convergent validity correlations (i.e., .76 to .92) with comparable measures, such as the Hopkins Symptom Checklist (HSCL), the Beck Depression Inventory (BDI), and the State-Trait Anxiety Inventory State Anxiety Scale (A-State). The PANAS also exhibits traitlike stability when used with long term instructions (Watson \& Clark).

Short-Form McGill Pain Questionnaire. The quality and intensity of participants' pain experience were measured using the Short-Form McGill Pain Questionnaire (SF- 
MPQ; Melzack, 1987). The SF-MPQ consists of 15 items that are divided into 11 sensory descriptors and 4 affective descriptors, and are rated on a four point intensity scale of 0 (none) to 3 (severe). The SF-MPQ also incorporates both a Present Pain Intensity index and a Visual Analog Scale to specify the overall intensity of the pain experience (See Appendix F for a copy of the SF-MPQ.). The SF-MPQ scores obtained from patients in post surgical and obstetrical wards and dental departments has demonstrated high internal consistency ( $\alpha=.73-.89)$ and its predictive validity is consistently high and significant (Burckhardt \& Jones, 2003; Melzack, 1987).

Posttraumatic Cognitions Inventory. Trauma-related thoughts and beliefs were assessed using the Posttraumatic Cognitions Inventory (PTCI; Foa, Ehlers, Clark, Tolin, \& Orsillo, 1999). The PTCI is a 36 item questionnaire that measures three constructs linked with trauma-related thoughts and beliefs: (a) negative cognitions about the world, (b) negative cognitions about self, and (c) self blame. Participants rated the extent to which they experienced such thoughts and feelings, using a 7-point scale. Research on non-clinical and clinical samples has indicated the PTCI has high reliability (Cronbach's $\alpha=.97$ ), and the PTCI has proven valid in discriminating both clinical and non-clinical participants who engage in more trauma-related cognitions. Traumatized individuals, as measured by the PTCI, scored significantly higher than nontraumatized individuals on all of the scales (Orsillo, 2001).

Beck Depression Inventory-II. The Beck Depression Inventory-II (BDI-II) consists of 21 items measuring the severity of depression (Steer, Clark, \& Beck, 1999). The BDI-II is composed of items relating to depressive symptoms such as hopelessness, irritability, guilt, fatigue, weight loss, and lack of interest in sex. The BDI-II shows high 
internal consistency $(\alpha=.92)$ and high convergent validity as is demonstrated by Pearson correlations between the BDI-II and the Depression scale of the SCL-90-R ( $r=.89)$ (Steer, Clark, \& Beck).

Anxiety Sensitivity Index. The Anxiety Sensitivity Index (ASI) consists of 16 statements associated with anxiety sensitivity, where participants rated their agreement with the items on a 5-point scale (Reiss, Peterson, Gursky, \& McNally, 1986). The ASI appears to measure fear of fear a well as the frequency of anxious or fearful experiences. The ASI demonstrates adequate test-retest reliability $(r=.71)$ across three years (Maller \& Reiss, 1992), and has been shown to discriminate between clients with anxiety disorders and college students. Additionally, the ASI has been found to possess strong internal consistency $(\alpha=.88)$ (Peterson $\&$ Heilbronner, 1987). Although a revised version of the ASI has been developed, the original ASI was used in the present study since more research has been conducted on its psychometric properties.

The MacArthur Scale of Subjective Social Status. The MacArthur Scale of Subjective Social Status is otherwise known as the SES Ladder, and is used as a measure of socioeconomic status. The SES Ladder asked for participants' perceptions of their status in society relative to other people in the United States. Typically, participants are presented with a pictorial form, but in this study participants were asked to imagine a ladder with ten rungs, and to choose where on the ladder they believe they currently stood, similar to a Likert rating of 1 to 10 . Research has demonstrated a moderately significant relation between the SES ladder, and traditional indicators of SES (e.g., education, financial security, occupation and wealth) (Singh-Manoux, Marmot \& Adler, 2005). See Appendix G for a copy of the SES Ladder. 


\section{Procedure}

Data collection utilized the internet based SONA system, which is web-based human subject management software used by West Virginia University. There were four components of this study: (a) the demographic and historical information section, (b) a section containing questionnaires pertaining to current functioning, (c) an autobiographical narrative section, and (d) a section containing questionnaires regarding functioning at the time they experienced their autobiographical narrative. Participation lasted approximately 32 minutes, but there was much variability in duration, as participation took place in an unstructured personal environment. Participation was contingent upon an online agreement to informed consent via the SONA system. Participants willing to take part in the study were given information about their rights as participants in the study, and received a brief introduction explaining the study. Participants were informed that they could discontinue the study at any time and could refuse to answer any question(s) without penalty. Participants were randomly assigned to groups (i.e., an emotionally painful situation, a physically painful situation, a traumatic situation, a depressing situation, or a joyful situation). Demographic and history information section.

After consent to the study, the following demographic information was collected: age, race or ethnicity, sex, history of chronic pain, and socioeconomic status. (See Appendix I for a copy of the demographics form used).

\section{Current functioning questionnaires section.}

After completing the demographic portion of the study, participants were asked to complete the Beck Depression Inventory-II and the Anxiety Sensitivity Index. These 
measures were used to measure symptoms of current depression and anxiety across all groups. Depression and anxiety have been found to be significantly correlated with the experience of emotional pain, and symptoms of anxiety and depression are known to relate to the experience of physical pain (Orbach, 2003; Price, 1999; VandenBos, 2007). Thus, the Beck Depression Inventory-II and the Anxiety Sensitivity Index were used to ensure the equivalence of groups on these two major affective areas.

\section{Autobiographical narrative section.}

After completing the aforementioned demographic information and questionnaires, participants were randomly assigned to write one of five autobiographical narratives of types of situations they may have experienced (i.e., an emotionally painful situation, a physically painful situation, a traumatic situation, a depressing situation, or a joyful situation). All participants received instructions including a short explanation of the type of situation that they were instructed to write about before they were asked to write their narratives. Participants were asked if they have ever experienced one of the five situations. If a participant indicated that they had not experienced the situation corresponding to the group that they were assigned, they were asked to write their narrative about a joyful situation. No participants indicated that they had not experienced a joyful situation. All participants were instructed to "please think of a specific situation" when they had experienced the situation they had been assigned. Participants then were asked to write an autobiographical narrative about the incident in which they experienced the situation. Based on the work of Leary and Springer (1998), details regarding the incident were requested to ensure that enough information regarding the incident were included in the written accounts. Separate spaces were provided to describe: (a) the 
events leading up to the situation, (b) precisely what happened that was either:

emotionally hurtful, physically hurtful, traumatic, depressing, or joyful, (c) how they felt, and (d) what happened afterwards. To help ensure that participants recalled an actual event, the participants were also asked to indicate the approximate date the event started, how long it lasted, and location of each event. Additionally, participants were asked to indicate the gender, age, and relationship to the participant of other persons involved with the event, if applicable. (See Appendices A through E for copies of the autobiographical narrative instructions).

\section{Prior Functioning Questionnaire section.}

Immediately after writing the narrative, participants were asked to rate how they felt when they experienced the situation they wrote about, and were instructed that their answers should reflect their most intense feelings during the event. All participants completed the Positive and Negative Affect Schedule, the Short-Form McGill Pain Questionnaire, and the Posttraumatic Cognitions Inventory. After finishing the questionnaires, participants were thanked for their time, provided with a list of local mental health services, and instructed that the study was completed.

\section{Content Analysis of Emotional Pain Vignettes}

\section{Ratings of group correspondence.}

Two trained graduate student research assistants independently read and rated the narratives on a $0-100$ Likert-type scale, indicating how much every narrative corresponded to each of the five groups (i.e., emotional pain, physical pain, trauma, depression and joy). There were two ratings for each narrative. The raters were masked to the condition participants wrote about. The raters were trained to criterion (i.e., 
agreement within 15 points on a $0-100$ Likert-type scale for five consecutive ratings) using practice narratives. The ratings of narratives were checked after each 25 were completed. Recalibration of the raters occurred after half of the data were collected to control for rater drift.

Categorization of situations.

Content analysis also was used to categorize the content of the situation participants wrote about in their vignettes. The analytical strategy was based on the low inference interpretation of qualitative data and representation of qualitative data in everyday language conducted by Bergh, Jakobsson, and Sjostrom (2007). The data were analyzed using the following process:

1. Familiarization of data, which consisted of reading vignette content twice.

2. Summarization of the content of each vignette into categories.

3. Modification of categories during the course of analysis.

4. Coding of all units of content, and organization of categories.

5. Calculating frequencies and percentages of categories (See Tables 10 through 14) Steps one and two of the categorization process were carried out by research assistants, who were not masked to the group to which participants were assigned. Steps three through five were carried out by the author, who also was not masked to participants' group assignment.

Results

\section{Data Reduction and Management}

There were 583 participants who enrolled in the SONA system to complete this study. Of these, 271 participants indicated that they had never experienced the situation 
of the group they were assigned to write about, and were assigned to write about a joyful experience by default. Assignment to write about the default joyful experience required participants to check a box indicating they had not experienced the situation of the group they were assigned to, and then exit the portion of the SONA system study they were in, and select the default joy portion of the study. Although, 271 participants continued to participate in the default joy group, only 46 of the 271 participants checked the box indicating they had never experienced their assigned situation. This missing data creates difficulty distinguishing which condition the 271 excluded participants were originally assigned to. Although this data could have been used to assess how many participants indicated they had not experienced the particular situation of the group to which they were assigned, these data are not available.

Data from these 271 participants were not included in the present analysis. No participants indicated that they had never had a joyful experience. Data from another 62 participants were considered unusable and were excluded due to incomplete answers to measures or vignettes. Data were considered unusable if more than three items on any measure were missing or if a vignette consisted of 12 words or less. Only data from the remaining 250 participants (50 in each group) were included in the final analysis.

\section{Demographics, Background Characteristics, and Equivalence of Groups}

The mean age of the sample was 20.0 years $(S D=2.7)$, and participants across groups did not differ significantly in age, $F(4,245)=2.16, p=.074$. There were 190 women $(76.0 \%)$ and 60 men $(24.0 \%)$, and participants across groups did not differ significantly according to sex, $F(4,245)=.927, p=.449$. The sex distribution by group can be seen in Table 1. There were no ethnicity and race differences among groups in terms of white 
versus non-white participants, $X^{2}(4, N=250)=26.9, p>.10$. Across the entire sample, there were 225 (90\%) whites, six (2.4\%) African Americans, five (2.0\%) Hispanics, five (2.0\%) Asians, five (2.0\%) Mixed Race or Ethnicity, three (1.2\%) Other, and one (0.4\%) Native American. Across the sample, the average rating of socioeconomic status on the SES Ladder was $5.8(S D=1.5)$. There were no differences among groups on the SES Ladder, $F(4,245)=0.79, p>.10$.

To further demonstrate the equivalence of groups, specifically in terms of prior pain experience and pain history, non-parametric tests were run on dichotomous data. There were no significant group differences in participants' report of current chronic pain ratings $X^{2}(4, N=250)=6.5, p>.10$, past chronic pain ratings $X^{2}(4, N=250)=8.0, p>.05$, current acute pain ratings $X^{2}(4, N=250)=6.2, p>.10$, or past acute pain ratings $X^{2}(4, N$ $=250)=4.0, p>.10$. Frequencies for the pain history across groups are shown in Table 2. There were no differences among groups on the ASI, $F(4,245)=0.98, p>.10$, partial $\eta^{2}$ $=.016$. Additionally, there were no group differences among groups on the BDI-II, $F(4$, $245)=0.63, p>.10$, partial $\eta^{2}=.01$. Means and standard deviations for the ASI and BDI-II across groups are shown in Table 3. Measures of internal Consistency for every measure are shown in Table 4.

\section{Primary Data Analysis}

Hypothesis 1: Positive and Negative Affect Differences among Groups

There were significant differences among groups on the PANAS for both positive $\operatorname{affect}\left(F[4,245]=60.51, p<.0005\right.$, partial $\eta^{2}=.50$. $)$ and negative affect $(F[4,245]=$ $25.48, p<.0005$, partial $\eta^{2}=.29$.). Hypothesis 1 was partially supported in that the emotional pain group reported higher negative affect ratings than either the physical pain 
or joy groups. There were no significant differences, however, between emotional pain, trauma, and depression. Table 5 presents the means and standard deviations for the PANAS across groups.

Also as predicted in Hypothesis 1, the joy group had the lowest negative affect ratings and the highest positive affect ratings among all groups. Table 5 presents these results.

Hypothesis 2: Pain Description Differences among Groups

There were significant differences among groups in sensory descriptions of pain on the SF-MPQ $\left(F[4,245]=20.1, p<.0005\right.$, partial $\left.\eta^{2}=.25\right)$. In addition, there were significant differences among groups in affective descriptions of pain on the SF-MPQ $\left(F[4,245]=23.0, p<.0005\right.$, partial $\left.\eta^{2}=.27\right)$. Finally, there were significant differences among groups on the overall pain evaluation rating of the SF-MPQ $(F[4,245]=33.0, \mathrm{p}$ $<.0005$, partial $\eta^{2}=.35$ ). Hypothesis 2 was supported in that sensory descriptions were greatest in the physical pain group. Also, hypothesis 2 was partially supported in that affective descriptions of pain differed significantly between the emotional pain group and both the physical pain and joy groups, but not the trauma or depression groups. Finally, hypothesis 2 was partially supported in that overall pain evaluation was rated as more severe in the emotional pain group than in the joy group (but not in comparison with either the trauma or depression groups); the physical pain group had significantly greater overall evaluative ratings than any other group except for the emotional pain group. Table 6 presents the means and standard deviations for the SF-MPQ across groups. Hypothesis 3: Trauma Rating Differences among Groups

There were significant differences among groups on the total score of the PTCI 
$\left(F[4,245]=3.9, p<.005\right.$, partial $\left.\eta^{2}=.05\right)$. Additionally, there were significant differences among group scores on all of the PTCI's subscales, including the Self Blame Scale $\left(F[4,245]=3.4, p<.05\right.$, partial $\left.\eta^{2}=.06\right)$, the Negative Cognitions About Self Scale $\left(F[4,245]=3.9, p<.005\right.$, partial $\left.\eta^{2}=.06\right)$, and the Negative Cognitions About the World Scale $\left(F[4,245]=3.5, p<.01\right.$, partial $\left.\eta^{2}=.05\right)$. Hypothesis 3 was partially supported in that participants in the joy group had the lowest total PTCI scores of any group. Additionally, as was predicted, participants in the depression group had significantly higher PTCI scores than the physical pain and joy groups on the negative cognitions about the world subscale. Post hoc analysis (using the Bonferroni correction to reduce the probability of Type I error inflation) found that participants in the emotional pain group also had significantly higher PTCI scores on the negative cognitions about the world subscale than the physical pain and joy groups. However, there were no significant differences between groups on negative cognitions about the world scores for the trauma group. In addition, the emotional pain group had no significant differences between any other groups on total PTCI scores. Participants in the depression group had significantly higher total PTCI scores than the trauma, physical pain, or joy groups. Table 7 presents the means and standard deviations for the PTCI across groups.

\section{Hypothesis 4: Judges’ Rating Differences among Groups}

Reliability of ratings. Intraclass correlation coefficients were calculated to assess the reliability of the two research assistants ratings' of the correspondence of the narratives correspondence to each of the five group categories. The two raters had an intraclass correlation of $r=.70, p<.0005$ for their ratings of emotional pain, $r=.97, p$ $<.0005$ for their ratings of physical pain, $r=.76, p<.0005$ for their ratings of trauma, $r$ 
$=.74, p<.0005$ for their ratings of depression, and $r=.99, p<.0005$ for their ratings of joy.

Differences among groups. A 5 (group) X 5 (rating category) mixed factors ANOVA was conducted, with repeated measures on the latter variable, yielding a significant interaction, $F(16,980)=120.0, p<.0005$, partial $\eta^{2}=.66$. There also was a main effect for rating category, $F(4,980)=19.6, p<.0005$, partial $\eta^{2}=.07$, but no main effect for group, $F(16,980)=0.01, p>.10$, partial $\eta^{2}<.0005$. Table 8 presents mean values and results of simple effects tests within rating categories. Ratings of emotional pain were greatest for the emotional pain vignette group, significantly different at the $\alpha$ $=.05$ level from all other groups, except for the depression group. Ratings of physical pain were greatest for the physical pain vignette group, differing significantly from all other groups at the $\alpha=.05$ level. Ratings of trauma were greatest for the trauma vignette group, significantly different at the $\alpha=.05$ level from all other groups, except for the emotional pain group. Ratings of depression were greatest for the depression vignette group, significantly different at the $\alpha=.05$ level from all other groups, except for the emotional pain group. Ratings of joy were greatest for the joy vignette group, differing significantly from all other groups at the $\alpha=.05$ level. Although ratings made on each of the five narrative categories were all greatest for their matching group, emotional pain ratings did not significantly differ from trauma ratings for the trauma group, and depression ratings did not significantly differ from ratings of emotional pain or trauma for their corresponding groups. Thus, hypothesis 4 received only partial support.

\section{Exploratory Data Analyses}

Word Count 
Each vignette was evaluated in terms of the number of words typed by the participant. Significant differences were found in the length of vignette among groups $\left(F[4,245]=3.4, \mathrm{p}<.01\right.$, partial $\eta^{2}=.05$. $)$. Participants used an average of 145.3 words when typing their vignette $(S D=123.1)$. Mean number of words (and standard deviations) are presented in Table 9.

\section{Categorization of situations.}

Each vignette was summarized and classified into categories reflecting the type of situation involved in the vignette. Participants described a variety of situations in each of the groups. There were 46 different categories that participants were classified into across all the groups. Romantic breakups were the most common vignette category, with 28 participants (11.2\%) reporting dissolution of romantic relationships. Participants reported breakups in the emotional pain group $(n=12)$, the trauma group $(n=1)$, and the depression group $(n=15)$. Sports-related injuries were the second most common category, with 26 participants (10.4\%) reporting injuries while performing in sporting activities. All participants reporting sport related injury were in the physical pain group ( $n$ $=26$ ). The third, fourth, and fifth most commonly categorized situations were the death of a family member other than a grandparent, the death of a grandparent, and the death of a friend, respectively. These three types of death of someone close to the participants combined were reported by 67 participants (26.8\%), with 26 participants $(10.4 \%)$ reporting the death of a family member other than a grandparent, 21 participants $(8.4 \%)$ reporting the death of a grandparent, and 20 participants $(8.0 \%)$ reporting the death of a friend. Participants reported the death of someone close to them in the emotional pain group $(n=21)$, the trauma group $(n=18)$, and the depression group $(n=15)$. 


\section{Pain Intensity}

Overall intensity of pain experienced was reported on the SF-MPQ along a Visual Analogue Scale (VAS). Pain intensity ratings were not included in any of the preliminary analysis. There were significant differences among groups on the pain intensity VAS $\left(F[4,242]=3.4, p<.01\right.$, partial $\left.\eta^{2}=.29\right)$, with the physical and emotional pain groups having the highest reported intensity; means and standard deviations of pain intensity are presented in Table 6 . The physical pain group had the highest reported intensity, which was significantly higher than the other groups except for those reporting emotional pain. The emotional pain group had significantly higher intensity of pain than the trauma and joy groups.

\section{Discussion}

The primary goals of this study were to systematically examine: (a) the affective experience of emotional pain, (b) the affective and sensory descriptors used to describe emotional pain, and (c) the relations, and overlap of symptoms and situations that emotional pain shares with similar constructs (i.e., depression, trauma, and physical pain). To attain these goals, 250 undergraduate students were randomly assigned to one of five groups in which they were asked to write about prior experiences with emotional pain, physical pain, trauma, depression, or joy. Equivalence of current depressive and anxious symptomology was assessed using the BDI-II and ASI. Affective, pain-related, and traumatic variables of interest were measured using the PANAS, SF-MPQ, and PCTI, respectively.

The study had four main findings:

1. The emotional pain group was found to have significantly higher negative 
affective ratings than the physical pain and joy groups, with no significant differences between either trauma or depression groups. Additionally, the joy group had the highest ratings of positive affect, and the lowest ratings of negative affect.

2. The affective descriptions of participants' emotional pain experience were significantly more severe than the physical pain and joy groups, with no significant differences between either trauma or depression groups. As expected, participants in the physical pain group endorsed a significantly greater sensory experience of pain. Additionally, both physical and emotional pain groups had the highest overall evaluations of the pain experience, although emotional pain did not significantly differ from depression and trauma.

3. Participants in the trauma group did not meet significantly more PTSD criteria than any other group, and in fact scored slightly lower than the emotional pain group, and significantly lower than the depression group. The emotional pain group did not score significantly higher than any other group, including the joy group, which was only significantly lower than participants in the depression group's total PCTI scores. Both the emotional pain and depression groups endorsed significantly more items on the PCTI reflecting negative cognitions about the world than the physical pain and joy groups. However, the emotional pain group scored the lowest on the PTCI self blame subscale, with significantly lower scores of self blame than the joy group. These findings of low internalization and self blame are contrary to the work of Orbach (2003), Bolger (1999), and Shneidman (1999), which suggests that self blame is an integral 
component of emotional pain. Similarly, negative thoughts about oneself were not found to be significantly greater in the trauma group, in contrast to the views of Beck et al. (2004), who assert the central role of negative thoughts directed at oneself in the trauma related cognitive responses of PTSD.

4. Ratings of narratives correspondence to each of the five groups had reasonable reliability across all groups. Intraclass correlations ranged from of $r=.70$ for ratings of emotional pain to $r=.99$ for ratings of joy. All intraclass correlation coefficients were significant at $p<.0005$. Ratings made on each of the five narrative categories were all greatest for their corresponding group. However, there were category ratings that did not correspond to the group participants were assigned to, and failed to differ significantly from the correctly corresponding category rating. Emotional pain ratings for the emotional pain group did not significantly differ from ratings of depression. Additionally, trauma ratings for the trauma group and depression ratings for the depression group did not significantly differ from ratings of emotional pain. Thus it appears that ratings of emotional pain, trauma, and depression clustered together more than emotional pain and physical pain ratings.

\section{Overall Findings}

All groups were considered equivalent on scores of current major affective functioning. There were no significant differences between groups on depressive and anxiety sensitivity symptoms, although the depression group endorsed slightly higher ratings of depressive symptoms, and the emotional pain group endorsed slightly lower ratings of anxiety sensitivity symptoms. It is no surprise that the participants in the group 
reporting depressive experiences endorsed slightly more depressive symptoms, though it is more difficult to explain the lower reported levels of anxiety sensitivity reported in the emotional pain group. All groups were randomly assigned, but also self selected. If a participant reported no prior depressive experiences, for example, they were switched to a joy group, although the data were excluded from the present study.

The four hypotheses of this study all received partial support. Contrary to previous predictions, no significant differences were found between emotional pain and either depression or trauma for endorsements of negative affect or affective descriptions of pain. In fact, participants in the depression group had (non-significantly) higher ratings of: (a) negative affect on the PANAS, (b) higher affective descriptions of pain on the SFMPQ, and (c) higher scores on all sub-scales of the PCTI, when compared with participants in the emotional pain group. Thus, the participants conveying depression consistently endorsed more negative affect and trauma-related cognitions (including self blame, and negative thoughts about oneself) than the emotional pain group. The findings of lower self reported negative affect and trauma related-thoughts among participants reporting emotional pain is in contrast with much of the emotional pain literature, which emphasizes self blame, internalizing, and an excess of negative affect (Baumeister, 1990; Bolger, 1999; Orbach, 2003; Orbach et al., 2003; Shneidman, 1999).

Additionally, the emotional pain group did not report more severe affective descriptions of pain. The findings of lower affective pain responses for emotional pain is contrary to the current neurological emotional pain literature which highlights the role of the neurological structures involved in the affective components of pain in response to emotional pain. The affective qualities of physical pain are clearly linked with the ACC, 
and all of the neuroimaging studies of emotional pain to date have found the ACC to be activated in response to induced emotional pain (Eisenberger, 2006; Eisenberger \& Lieberman, 2004; Eisenberger et al., 2003; Gündel et al., 2003; Mee et al., 2006; Najib et al.,2004 Panksepp, 2003; Rainville, 2002).

Although the majority of ratings for each of the five narrative categories all matched with their corresponding group, some ratings failed to correctly identify the actual group to which participants were assigned. These findings of the ratings of participants' written accounts indicate that vignettes from the emotional pain, depression and trauma groups may have had similarities in their content. This overlap in classification suggests some difficulty in differentiating emotional pain from trauma, and even more so for depression. These findings of similarities in ratings of emotional pain and depression are generally consistent with previous exploratory literature on emotional pain which found moderate correlations for emotional pain, depression, and anxiety, and provides further support for the partial overlap found between depression and emotional pain by Orbach (2003).

It is possible that the difficulty distinguishing emotional pain from the experience of depression and trauma is in some ways related to the way emotional pain has been previously conceptualized. Emotional pain may be a higher order factor for depression and trauma, and even physical pain in some circumstances. It could be that emotional pain is not as distinguishable from depression or trauma because it is a component of these experiences. Thus, emotional pain's status as a distinct, individual experience has yet to be determined. 


\section{Exploratory Findings}

There are a number of interesting results that were conducted to further explore the data in addition to the original analyses that were planned as part of the study. These findings are discussed here tentatively, and because these exploratory analyses were not planned as part of the original experimental design, greater control was implemented to reduce the probability of Type I error by reducing alpha to $\alpha=.01$.

\section{Word Count}

Participants' vignettes were highly variable in length, and for the most part appeared very candid and of high quality. Participants across groups averaged 145 words for their vignettes, although the trauma group averaged considerably more words at 192, and the physical pain group averaged significantly less at only 105 words. This finding may correspond to Smyth's (1998) conclusions that individuals may have a strong desire to bring up traumatic events, but may not due to social constraints. Thus, written expression may provide an alternative when verbal communication is not socially acceptable.

\section{Categorization of situations.}

Although participants expressed a wide variety of situations across all the groups, there was an overlap in the type of situations participants wrote about, particularly in the emotional pain, depression, and trauma groups. Participants reported similar numbers of breakups in the emotional pain group $(n=12)$, and the depression group $(n=15)$, as well as similar numbers of deaths of people close to them in the emotional pain group $(n=21)$, the trauma group $(n=18)$, and the depression group $(n=15)$. These results suggest various emotional responses to life events, consistent with extant theories of emotion and 
emotional disorders. In some cases, emotional pain may be antecedent to the experience of depression and trauma.

\section{Pain Intensity}

As expected, physical and emotional pain groups reported the highest pain intensity. Although the joy group reported the lowest pain intensity, it is interesting that participants reporting a joyful experience endorsed any pain at all as the joy group was meant to be a control group. It is possible that some sort of reactivity or bias took place with participants in the joy group. Perhaps a form of subject expectancy was in effect, in which participants who had most likely not experienced any pain during their joyful experience were presented with a pain measure, which influenced the participants to believe they were expected to report pain, which facilitated their response. Additionally, there could have been an effect of regression toward the mean, with participants who had filled out a number of measures in which they were not expected to endorse many items, such as traumatic beliefs in the PCTI (which would be far from the mean), beginning to select scores closer to the mean. These same forms of bias may have affected the joy group's surprisingly elevated scores on the PCTI, with the PCTI total score only being statistically smaller than the depression group (See Table 7). Thus, it appears that the use of measures of pain and trauma (SF-MPQ and PTCI) may not be valid for use in those reflecting purely joyful content.

\section{Limitations}

One of the limitations of this study was the use of autobiographical narratives for studying emotional pain. Although asking participants to recall and relate past experiences is a practical tool due to the complexities of recreating emotional pain in a 
laboratory setting, there are some intrinsic limitations to their use. It is likely that some when asking participants to recall a previous event, that some sort of heuristic or bias was used in choosing that specific event, or in selectively omitting humiliating or negative details of the event. Additionally, it is questionable as to whether or not the reported event is representative of all of their particular experiences of that type of event. However, the instructions participants received to think of an event that was experienced "in an intense way that was out of the ordinary" and that was "significant enough that you should be able to remember it if it happened at any time in your life" should ensure that reported event were consistently memorable. (See Appendices A through E for instructions for the writing conditions).

Another limitation of this study was the inherent lack of structure in conducting an internet-based study on a relatively newly explored construct that lacks a widely agreed upon operational definition. While it appears that many people report experiencing emotional pain, it still is unclear whether it is truly an independent experiential entity or whether emotional pain can be subsumed by some other related aversive experience, or is an antecedent to, or a higher order factor for these states.

It appears that participants' written vignettes may not always have exactly met the criteria specified by the instructions for the writing conditions. For example, 4 out of the 50 participants in the physical pain group endorsed pain caused by social loss or perceived interpersonal rejection (as shown in Table 11), although instructions for the physical pain group clearly differentiate physical from emotional pain in that physical pain is felt in response to direct physical stimuli (as shown in Appendix B).

It also is possible that since this study was carried out anonymously over the 
internet, with extra credit compensation, that some participants were more likely to endorse experiencing the situation of the group to which they were assigned, even if it their experience did not fit the criteria of the situation they were assigned. This idea is highly speculative, but it may be that individuals are less likely to endorse an experience they had not experienced in a face to face interaction, compared to when on the computer at home. A possibility is that the reward of extra credit and complete anonymity of responding led to participants endorsing experiences different from the situations of the groups they were assigned to, such as a participant using an emotionally painful experience for the trauma or depression group.

Another possible limitation of this study was that only one person was responsible for the categorization and organization of the situational content of participants' vignettes. This strategy allowed a higher likelihood of individual bias affecting the content analysis of the situations in participants' vignettes.

Additionally, the content of participants' vignettes appears to be age-related. For example, in the emotional pain group, the most frequently reported distress was associated with grandparents' deaths, or the breakup of relationships with a boyfriend or girlfriend (see Table 10). Thus, because of the relatively young age of the sample, participants may not have experienced the breadth of situations representative of emotional pain. Nevertheless, any age group of participants would be affected by their developmental stage and the issues associated with it (e.g., chronic illness in older adults).

\section{Future Research}

Future studies that using different methodology are needed to test and replicate the findings of the present study, and the sparse non-neurological empirical emotional 
pain literature. Different sampling techniques, such as providing multiple writing assignments (perhaps through the use of a diary), or creative ways of inducing emotional pain in a laboratory setting, are needed. Studying emotional pain in a naturalistic setting, such as a hospice or hospital setting could prove beneficial. Additionally, when autobiographical narratives are used, a tactic of saturation could be taken by requesting multiple narratives from a single participant, which could increase the representativeness of responses by exhausting participant's repertoire of a particular type of event. Another method could require participants to write about multiple types of prior experiences, and then require them to distinguish the differences between their experiences, which would allow them to interpret their experiences rather than an external rater. Another consideration for future research could involve sampling different populations, such as community samples, in order to have more representative age groups, and to increase the generalizability of findings. 


\section{References}

American Psychiatric Association. (1994). Diagnostic and statistical manual of mental disorders ( $4^{\text {th }}$ ed.). Washington, DC: Author.

Arntz, A., \& Schmidt, A. J. M. (1989). Perceived control and the experience of pain. In A. Steptoe \& A. Appels (Eds.), Stress, personal control and health (pp. 131-162). New York: Wiley.

Beck, J. G., Coffey, S. F., Palyo, S. A., Gudmundsdottir, B., Miller, L. M., \& Colder, C. R. (2004). Psychometric properties of the Posttraumatic Cognitions Inventory (PTCI): A replication with motor vehicle accident survivors. Psychological Assessment, 16, 289-298.

Bolger, E. (1999). Grounded theory analysis of emotional pain. Psychotherapy research, 99, 342-362.

Baumeister, R. F. (1990). Suicide as escape from self. Psychological Review, 97, 90-113. Bergh, I., Jakobsson, E., \& Sjostrom, B. (2007). Worst experiences of pain and conceptions of worst pain imaginable among nursing students. Journal of Advanced Nursing, 61, 484-491.

Burckhardt, C. S., \& Jones, K. D. (2003). Adult measures of pain: The McGill Pain Questionnaire (MPQ), Rheumatoid Arthritis Pain Scale (RAPS), Short-Form McGill Pain Questionnaire (SF-MPQ), Verbal Descriptive Scale (VDS), Visual Analog Scale (VAS), and West Haven-Yale Multidisciplinary Pain Inventory (WHYMPI). Arthritis \& Rheumatism, 49(Suppl. 5), 96-104. 
Eisenberger, N. I., \& Lieberman, M. D. (2004). Why rejection hurts: A common neural alarm system for physical and social pain. Trends in Cognitive Sciences, 8, 294300.

Eisenberger, N. I., Lieberman, M. D., \& Williams, K. D. (2003). Does rejection hurt? An fMRI study of social exclusion. Science, 302, 290-292.

Eisenberger, N. I., Jarcho, J. M., Lieberman, M. D., \& Naliboff, B. D. (2006). An experimental study of shared sensitivity to physical pain and social rejection. Pain, $126,132-138$.

Elliott, D. M. (1997). Traumatic events: Prevalence and delayed recall in the general population. Journal of Consulting and Clinical Psychology, 65, 811-820.

Erdfelder, E., Faul, F., \& Buchner, A. (1996). GPOWER: A general power analysis program. Behavior Research Methods, Instruments, \& Computers, 28, 1-11.

Foa, E. B., Ehlers, A., Clark, D.M., Tolin, D. F., \& Orsillo, S. M. (1999). The posttraumatic cognitions inventory (PTCI): Development and validation. Psychological Assessment, 11, 303-314.

Gatchel, R. J. (1999). Perspectives on pain: A historical overview. In R. J. Gatchel \& D. C. Turk (Eds.), Psychosocial factors in pain: Critical perspectives (pp. 3-17). New York: The Guilford Press.

Greenberg, L., \& Bolger, E. (2001). An emotion focused approach to the overregulation of emotion and emotional pain. Psychotherapy in practice, 57, 197-211.

Gündel, H., O’Connor, M.F., Littrell, L., Fort, C., \& Lane, R.D. (2003). Functional Neuroanatomy of grief: An fMRI study. American Journal of Psychiatry, 160, 1946-1953. 
International Association for the Study of Pain Task Force on Taxonomy. (1994). Classification of chronic pain: Descriptions of chronic pain syndromes and definitions of pain terms, ( $2^{\text {nd }}$ ed.; pp. 209-214). Seattle, WA: IASP Press.

Keppel, G., \& Wickens, T. D. (2004) Design and analysis: A researcher's handbookFourth Ed. Upper Saddle River, NJ: Pearson Education, Inc.

Kubany, E. S., Leisen, M. B., \& Kaplan, A. S. (2000). Development and preliminary validation of a brief broad-spectrum measure of trauma exposure: The Traumatic Life Events Questionnaire. Psychological Assessment, 12, 210-224.

Leary, M. R., Springer, C., Negel, L., Ansell, E., \& Evans, K. (1998). The causes, phenomenology, and consequences of hurt feelings. Journal of Personality and Social Psychology, 74, 1225-1237.

Macdonald, G., \& Leary, M. R. (2005). Why does social exclusion hurt? The relationship between social and physical pain. Psychological Bulletin, 131, 202-223.

Maller, R. G., \& Reiss, S. (1992). Anxiety sensitivity in 1984 and panic attacks in 1987. Journal of Anxiety Disorders, 6, 241-247.

Mee, S., Bunney, B. G., Reist, C., Potkin, S. G., \& Bunney, W. E. (2006). Psychological pain: A review of evidence. Journal of Psychiatric Research, 40, 680-690.

Melzack, R. (1993). Pain: Past, present and future. Canadian Journal of Experimental Psychology, 47, 615-629.

Melzack, R. (1987). The Short-Form McGill Pain Questionnaire. Pain, 30, 191-197.

Najib, A., Lorberbaum, J. P., Kose, S., Bohning, D. E., \& George, M. S. (2004). Regional brain activity in women grieving a romantic relationship breakup. American Journal of Psychiatry, 161, 2245-2256. 
Orbach, I. (2003). Mental pain and suicide. Israeli Journal of Psychiatry Related Science, 40, 191-201.

Orbach, I., Mikulincer, M., Sirota P., \& Schectman-Gilboa, E. (2003). Mental pain: A multidimensional operationalization and definition. Suicide and Life Threatening Behavior, 33, 219-230.

Orbach, I., Milstein, I., Har-Even, D., Apter, A., Tiano, S., \& Elizur, A. (1991). A multiattitude suicide tendency scale for adolescents. Psychological Assessment, 3, 398404.

Orsillo, S. M. (2001). Measures for acute stress disorder and posttraumatic stress disorder. In M. M. Antony, S. M. Orsillo, \& L. Roemer (Eds.), Practitioners Guide to Emperically Based Measures of Anxiety (pp. 255-303). New York: Kluwer Academic / Plenum Publishers.

Panksepp, J. (2003). Feeling the pain of social loss. Science, 302, 237-238.

Pennebaker, J. W. (1997). Writing about emotional experiences as a therapeutic process. Psychological Science, 8, 162-166.

Peterson, R. A., \& Heilbronner, R. L. (1987). The Anxiety Sensitivity Index: Construct validity and factor analytic structure. Journal of Anxiety Disorders, 1, 117-121.

Plutchik, R. (2003). Emotions and life: Perspectives from psychology, biology and evolution. Washington DC: American Psychological Association.

Price, D. D. (1999). Psychological mechanisms of pain and analgesia. In Progress in pain research and management. Vol. 15. Seattle: IASP Press.

Rainville, P. (2002). Brain mechanisms of pain affect and pain modulation. Current Opinion in Neurobiology, 12, 195-204. 
Rainville, P., Duncan, G. H., Price, D. D., Carrier, B., \& Bushnell, M. C. (1997) Pain affect encoded in human anterior cingulate but not somatosensory cortex. Science, 277, 968-971.

Reiss, S., Peterson, R. A., Gursky, D. M., \& McNally, R. J. (1986). Anxiety sensitivity, anxiety frequency and the predictions of fearfulness. Behaviour Research and Therapy, 24, 1-8.

Robinson, M. E. \& Riley, J. L., III. (1999). The role of emotion in pain. In R. J. Gatchel \& D. C. Turk (Eds.), Psychosocial factors in pain: Critical perspectives (pp. 7488). New York: The Guilford Press.

Sheehan, C. (2006, August 26). A mother's pain. CommonDreams.org News Center. Retrieved March 3, 2007, from http://www.commondreams.org/views06/082622.htm.

Singh-Manoux, A., Marmot, M.G., \& Adler, N.E. (2005). Does subjective social status predict health and change in health status better than objective status? Psychosomatic Medicine, 67, 855-861.

Smyth, J. M. (1998). Written emotional expression: Effect sizes, outcome types, and moderating variables. Journal of Consulting and Clinical Psychology, 66, 174184.

Steer, R. A., Clark, D. A., \& Beck, A. T. (1999). Common and specific dimensions of self-reported anxiety and depression: The BDI-II versus the BDI-IA. Behavior Research and Therapy, 37, 183-190.

Shneidman, E. S. (1999). The psychological pain assessment scale. Suicide and LifeThreatening Behavior, 29, 287-293. 
Thornhill, R., \& Thornhill, N. W. (1989). The evolution of psychological pain. In R. Bell (Ed.), Sociobiology and the social sciences (pp. 73-103). Lubbock: Texas Tech University Press.

Turk, D. C., \& Flor, H. (1999). Chronic pain: A biobehavioral perspective. In R. J. Gatchel \& D. C. Turk (Eds.), Psychosocial factors in pain: Critical perspectives (pp.18-34). New York: The Guilford Press.

VandenBos, G. R. (Ed.). (2007). APA dictionary of psychology. Washington, DC: American Psychiatric Association.

Watson, D. \& Clark, L. A. (1988). Development and validation of brief measures of positive and negative affect: The PANAS scales. Journal of Personality and Social Psychology, 54, 1063-1070.

Willis, W. D. J., \& Westlund, K. N. (1997). Neuroanatomy of the pain system and of the pathways that modulate pain. Journal of Clinical Neuropsychology, 14, 2-31. 


\section{Appendix A}

\section{Instructions and Explanation of the Emotional Pain Writing Condition}

Emotional pain is felt in response to psychological suffering that is associated with a distressing life situation, in which may occur in the absence of physical pain.

Have you ever had a time that you felt emotional pain in an intense way that was out of the ordinary? We are referring to emotional pain that would be significant enough that you should be able to remember it if it happened at any time in your life.

Have you ever felt emotional pain in this intense way? (Please choose "yes" or "no" below.)

\section{$\mathrm{Yes} / \mathrm{No}$}

If you indicated "yes," how many such intensely emotionally painful times have you had in your life in total? If you have never had an intensely emotionally painful time in your life, choose "0." (Please choose an answer below.)

$$
0,1,2,3,4,5,6-10,11-15,16 \text { or more }
$$

Please help us learn more about the experience of emotional pain by thinking about one specific time in which you felt intense emotional pain and write about it. In the sections below, you will be asked to describe: (a) the events leading up to the situation, (b) precisely what happened that led to your depression, (c) how you felt, (d) the approximate date, (e) the location, if that is relevant, (f) other persons involved, if any, and their gender, age, relationship to you, and role in the situation, and (g) what happened afterwards. 


\section{Appendix B}

Instructions and Explanation of the Physical Pain Writing Condition

Physical pain is felt in response to use of your body, injuries that happen to your body, or health-related problems. Physical pain can be short- or long-term.

Have you ever had a time that you felt physical pain in an intense way that was out of the ordinary? We are referring to physical pain that would be significant enough that you should be able to remember it if it happened at any time in your life.

Have you ever felt physical pain in this intense way? (Please choose "yes" or "no" below.)

\section{Yes/No}

If you indicated "yes," how many such intense physically painful times have you had in your life in total? If you have never had an intensely physically painful time in your life, choose "0." (Please choose an answer below.)

$$
0,1,2,3,4,5,6-10,11-15,16 \text { or more }
$$

Please help us learn more about the experience of physical pain by thinking about one specific time in which you felt intense physical pain and write about it. In the sections below, you will be asked to describe: (a) the events leading up to the situation, (b) precisely what happened that led to your depression, (c) how you felt, (d) the approximate date, (e) the location, if that is relevant, (f) other persons involved, if any, and their gender, age, relationship to you, and role in the situation, and (g) what happened afterwards. 


\section{Appendix C}

Instructions and Explanation of the Traumatic Experience Writing Condition Experiencing traumatic events can produce emotional reactions of fear, helplessness, and/or horror. Trauma often involves a threat to one's life or well-being.

Have you ever had a time that you felt trauma in an intense way that was out of the ordinary? We are referring to a traumatic event that would be significant enough that you should be able to remember it if it happened at any time in your life.

Have you ever felt trauma in this intense way? (Please choose "yes" or "no" below.)

\section{Yes/No}

If you indicated "yes," how many such intensely traumatic times have you had in your life in total? If you have never had an intensely traumatic time in your life, choose "0." (Please choose an answer below.)

$$
0,1,2,3,4,5,6-10,11-15,16 \text { or more }
$$

Please help us learn more about the experience of traumatic events by thinking about one specific time in which you felt intensely traumatized and writing about it. In the sections below, you will be asked to describe: (a) the events leading up to the situation, (b) precisely what happened that led to your depression, (c) how you felt, (d) the approximate date, (e) the location, if that is relevant, (f) other persons involved, if any, and their gender, age, relationship to you, and role in the situation, and (g) what happened afterwards. 


\section{Appendix D}

\section{$\underline{\text { Instructions and Explanation of the Joyful Experience Writing Condition }}$}

Joy is felt in response to happy events, in which there is delight, satisfaction, gladness, and/or being elated. Joy often involves being involved in positive situations.

Have you ever had a time that you felt joy in an intense way that was out of the ordinary? We are referring to joy that would be significant enough that you should be able to remember it if it happened at any time in your life.

Have you ever felt joy in this intense way? (Please choose "yes" or "no" below.)

\section{Yes/No}

If you indicated "yes," how many such intensely joyful times have you had in your life in total? If you have never had an intensely joyful time in your life, choose "0." (Please choose an answer below.)

$$
0,1,2,3,4,5,6-10,11-15,16 \text { or more }
$$

Please help us learn more about the experience of joy by thinking about one specific time in which you felt intensely joyful and writing about it. In the sections below, you will be asked to describe: (a) the events leading up to the situation, (b) precisely what happened that led to your depression, (c) how you felt, (d) the approximate date, (e) the location, if that is relevant, (f) other persons involved, if any, and their gender, age, relationship to you, and role in the situation, and (g) what happened afterwards. 


\section{Appendix E}

\section{Instructions and Explanation of the Depressed Experience Writing Condition} Depression is felt as sadness, low mood, or loss of pleasure. Depression may involve feeling sad, fatigued, unmotivated, irritable, lazy, and/or apathy.

Have you ever had a time that you felt depressed in an intense way that was out of the ordinary? We are referring to depression that would be significant enough that you should be able to remember it if it happened at any time in your life.

Have you ever felt depressed in this intense way? (Please choose "yes" or "no" below.)

$$
\text { Yes/No }
$$

If you indicated "yes," how many such intensely depressing times have you had in your life in total? If you have never had an intensely depressing time in your life, choose "0." (Please choose an answer below.)

$$
0,1,2,3,4,5,6-10,11-15,16 \text { or more }
$$

Please help us learn more about the experience of depression by thinking about one specific time in which you felt intensely depressed and writing about it. In the sections below, you will be asked to describe: (a) the events leading up to the situation, (b) precisely what happened that led to your depression, (c) how you felt, (d) the approximate date, (e) the location, if that is relevant, (f) other persons involved, if any, and their gender, age, relationship to you, and role in the situation, and (g) what happened afterwards. 


\section{Appendix F}

I. Pain Rating Index (PRI):

SF-MPQ

The words below describe average pain. Please choose the column that represents the degree to which you felt that type of pain.

\begin{tabular}{|l|c|c|c|c|}
\hline & None & Mild & Moderate & Severe \\
\hline Throbbing & 0 & 1 & 2 & 3 \\
\hline Shooting & 0 & 1 & 2 & 3 \\
\hline Stabbing & 0 & 1 & 2 & 3 \\
\hline Sharp & 0 & 1 & 2 & 3 \\
\hline Cramping & 0 & 1 & 2 & 3 \\
\hline Gnawing & 0 & 1 & 2 & 3 \\
\hline Hot-Burning & 0 & 1 & 2 & 3 \\
\hline Aching & 0 & 1 & 2 & 3 \\
\hline Heavy & 0 & 1 & 2 & 3 \\
\hline Tender & 0 & 1 & 2 & 3 \\
\hline Splitting & 0 & 1 & 2 & 3 \\
\hline Tiring- & 0 & 1 & 2 & 3 \\
Exhausting & & & 2 & 3 \\
\hline Sickening & 0 & 1 & 2 & 3 \\
\hline Fearful & 0 & 1 & 2 & 3 \\
\hline Punishing-Cruel & 0 & 1 & & \\
\hline
\end{tabular}

II. Pain Intensity (PI)-Visual Analog Scale (VAS). Please pick a number from $0-100$ to describe your pain intensity:

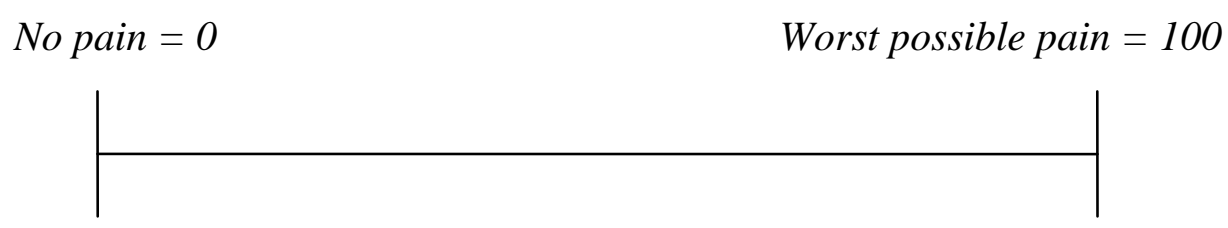

III. Evaluative overall intensity of total pain experience. Choose the appropriate column:

\begin{tabular}{|l|l|}
\hline \multicolumn{2}{|l|}{ Evaluative } \\
\hline 0 & No pain \\
\hline 1 & Mild \\
\hline 2 & Discomforting \\
\hline 3 & Distressing \\
\hline 4 & Horrible \\
\hline 5 & Excruciating \\
\hline
\end{tabular}




\section{Appendix G}

Imagine a ladder with 10 rungs, with each of the 10 rungs being numbered. The top rung is labeled with the number "10", the rung second from the top is labeled "9", and each lower rung has a smaller number, with the bottom rung labeled " 1 ".

Think of this ladder as representing where people stand in the United States. At the TOP of the ladder are the people who are best off - those who have the most money, the most education, and the most respected jobs. At the BOTTOM are the people who have the least money, least education, and the least respected jobs or no job. The higher up you are on this ladder, the closer you are to the people at the very top; the lower you are, the closer you are to the people at the very bottom.

\section{WHERE WOULD YOU PLACE YOURSELF ON THIS LADDER?}

Please enter the number of the rung where you think you stand at this time in your life, relative to other people in the United States. 
Appendix $\mathrm{H}$

Thank you for participating!

\section{Morgantown Area Mental Health Resources}

If you desire mental health services after completing the study Writing about Life Experiences and Emotions, here is a list of three resources for mental health services in the Morgantown area:

\section{Carruth Center for Counseling and Psychological Services}

Student Services Center

West Virginia University

Morgantown, WV 26506

(304) 293-4431

Hours: Monday through Friday, 8:15 AM to 4:45 PM

\section{Quin Curtis Center}

Life Sciences Building, Suite 1232

West Virginia University

Morgantown, WV 26506

(304) 293-2001 x 31671

Hours: Monday through Thursday, 9:00 AM to 5:00 PM

\section{Chestnut Ridge Hospital}

930 Chestnut Ridge Road

Morgantown, WV 26505

(304) 598-6400

24 hours-a-day WVU Healthline: (800) 982-8242 
Appendix I

Demographics and History Form

1.) What is your gender?

1. Male

2. Female

2.) What is your age?

3.) What is your race or ethnic background?

1. White/Caucasian

2. African-American

3. Hispanic

4. Asian

5. Native American

6. Mixed

7. Other

4.) Do you now have significant physical pain that has lasted 6 months or more?

(YES/NO/ I do not want to provide an answer for this question)

(If NO, please choose to decline the next 5 questions after this one)

- Please enter how severe would you rate that pain, on a scale from 0 - 100 (with 0 being "no pain" and 100 being "the maximum pain possible")

- Please enter how long has this pain lasted (in months)

- Please enter the number of days a week you experience this pain

- What is the source of this pain?

- Do you have any other significant pain now that has lasted 6 months or more? (YES/NO/I do not want to provide an answer for this question)

5.) (Besides any pain just discussed) Have you ever had significant physical pain lasting 6 months or more? (YES/NO)

(If NO, please choose to decline the next 5 questions after this one)

- Please enter how severe would you rate that pain, on a scale from $0-100$ (with 0 being "no pain" and 100 being "the maximum pain possible")

- Please enter how long has this pain lasted (in months)

- Please enter the number of days a week you experience this pain

- What is the source of this pain?

- Have you ever had any other significant pain that has lasted 6 months or more? (YES/NO/ I do not want to provide an answer for this question)

6.) Do you now have significant physical pain that has lasted less than 6 months?

(YES/NO/ I do not want to provide an answer for this question)

(If NO, please choose to decline the next 5 questions after this one) 
- Please enter how severe would you rate that pain, on a scale from $0-100$ (with 0 being "no pain" and 100 being "the maximum pain possible")

- Please enter how long has this pain lasted (in months)

- Please enter the number of days a week you experience this pain

- What is the source of this pain?

- Do you have any other significant pain now that has lasted less than 6 months? (YES/NO)

7.) (Besides any pain just discussed) Have you ever had significant physical pain lasting less than 6 months? (YES/NO/ I do not want to provide an answer for this question)

(If NO, please choose to decline the next 5 questions after this one)

- Please enter how severe would you rate that pain, on a scale from $0-100$ (with 0 being "no pain" and 100 being "the maximum pain possible")

- Please enter how long has this pain lasted (in months)

- Please enter the number of days a week you experience this pain

- What is the source of this pain?

- Have you ever had any other significant pain that has lasted less than 6 months? (YES/NO) 


\section{Table 1.}

Sex Distribution by Group

\begin{tabular}{lccc}
\hline & $\begin{array}{c}\text { Number of } \\
\text { Males }\end{array}$ & $\begin{array}{c}\text { Number of } \\
\text { Females }\end{array}$ & $\begin{array}{c}\% \\
\text { Male/Female }\end{array}$ \\
\hline All Participants & 60 & 190 & $24 / 76$ \\
Emotional Pain & 10 & 40 & $20 / 80$ \\
Physical Pain & 15 & 35 & $30 / 70$ \\
Trauma & 13 & 37 & $26 / 74$ \\
Depression & 8 & 42 & $16 / 84$ \\
Joy & 14 & 36 & $28 / 72$ \\
\hline
\end{tabular}




\section{Table 2.}

\section{Pain History}

\section{Frequency}

Current Chronic Pain Rating

Emotional Pain

5

Physical Pain

7

Trauma

1

Depression

4

Joy

2

Past Chronic Pain Rating

Emotional Pain

3

Physical Pain

12

Trauma

6

Depression

8

Joy

5

Current Acute Pain Rating

Emotional Pain

12

Physical Pain

Trauma

8

Depression

3

Joy

9

Past Acute Pain Rating

Emotional Pain

Physical Pain

Trauma

Depression

Joy 


\section{Table 3.}

Means (and Standard Deviations) for ASI and BDI-II Across Groups

\begin{tabular}{lcc} 
& ASI & BDI-II \\
\hline Emotional Pain & $18.3(8.9)$ & $11.9(8.3)$ \\
Physical Pain & $21.1(11.2)$ & $13.0(11.0)$ \\
Trauma & $22.1(12.6)$ & $12.4(9.0)$ \\
Depression & $22.1(12.6)$ & $14.5(11.1)$ \\
Joy & $20.9(11.2)$ & $11.9(9.0)$ \\
\hline
\end{tabular}

Note. $n=50$ for each group 
Table 4.

Internal Consistencies for all Measures (ASI, BDI-II, SF-MPQ, PANAS, and PTCI)

\begin{tabular}{lll} 
Group & $\begin{array}{l}\text { Chronbach's } \\
\text { Alpha }\end{array}$ & $\begin{array}{l}\text { Chronbach's Alpha based } \\
\text { on Standardized Items }\end{array}$ \\
\hline ASI & .90 & .90 \\
BDI-II & .92 & .92 \\
SF-MPQ & .40 & .92 \\
$\begin{array}{l}\text { PANAS } \\
\text { positive affect scale } \\
\text { negative affect scale }\end{array}$ & .90 & .80 \\
$\begin{array}{l}\text { PTCI } \\
\text { P. }\end{array}$ & .95 & .80 \\
\end{tabular}


Table 5.

Means (and Standard Deviations) for PANAS Across Groups

\begin{tabular}{lrr} 
Group & $\begin{array}{c}\text { Positive } \\
\text { Affect }\end{array}$ & $\begin{array}{c}\text { Negative } \\
\text { Affect }\end{array}$ \\
\hline Emotional Pain & $19.8(6.7)^{\mathrm{a}}$ & $30.9(7.3)^{\mathrm{a}, \mathrm{b}}$ \\
Physical Pain & $21.0(7.0)^{\mathrm{a}, \mathrm{b}}$ & $27.8(6.4)^{\mathrm{c}}$ \\
Trauma & $23.6(9.1)^{\mathrm{b}}$ & $30.6(7.9)^{\mathrm{a}, \mathrm{b}, \mathrm{c}}$ \\
Depression & $20.6(7.9)^{\mathrm{a}, \mathrm{b}}$ & $31.3(7.9)^{\mathrm{b}}$ \\
Joy & $39.9(7.5)^{\mathrm{c}}$ & $19.0(6.6)^{\mathrm{d}}$
\end{tabular}

Note. PANAS $=$ Positive and Negative Affect Schedule. In each column, means that do not share a common superscript differ significantly at $p<0.05$. 
Table 6.

Means (and Standard Deviations) for SF-MPQ Across Groups

\begin{tabular}{lllll} 
Group & $\begin{array}{l}\text { Affective } \\
\text { Scale }\end{array}$ & $\begin{array}{l}\text { Sensory } \\
\text { Scale }\end{array}$ & $\begin{array}{l}\text { Overall } \\
\text { Intensity Rating }\end{array}$ & $\begin{array}{l}\text { Pain Intensity } \\
\text { VAS }\end{array}$ \\
Emotional Pain & $6.9(3.1)^{\mathrm{a}}$ & $11.1(8.5)^{\mathrm{a}, \mathrm{c}}$ & $3.3(1.1)^{\mathrm{a}, \mathrm{b}}$ & $66.0(25.6)^{\mathrm{a}, \mathrm{c}}$ \\
Physical Pain & $5.6(2.7)^{\mathrm{b}}$ & $19.2(6.0)^{\mathrm{b}}$ & $3.7(0.8)^{\mathrm{a}}$ & $73.9(18.9)^{\mathrm{a}}$ \\
Trauma & $7.2(2.8)^{\mathrm{a}}$ & $8.3(6.7)^{\mathrm{a}, \mathrm{d}}$ & $3.0(1.3)^{\mathrm{b}}$ & $52.1(35.4)^{\mathrm{b}}$ \\
Depression & $7.2(3.2)^{\mathrm{a}}$ & $13.0(9.3)^{\mathrm{c}}$ & $3.2(1.4)^{\mathrm{b}}$ & $60.4(30.6)^{\mathrm{b}, \mathrm{c}}$ \\
Joy & $2.5(3.0)^{\mathrm{c}}$ & $6.2(8.4)^{\mathrm{d}}$ & $1.1(1.5)^{\mathrm{c}}$ & $20.8(31.0)^{\mathrm{d}}$ \\
\hline
\end{tabular}

Note. SF-MPQ = Short-Form McGill Pain Questionnaire. In each column, means that do not share a common superscript differ significantly at $p<0.05$. 
Table 7.

Means (and Standard Deviations) for PTCI Across Groups

\begin{tabular}{cccccc} 
& \multicolumn{2}{c}{$\begin{array}{l}\text { Negative } \\
\text { Cognitions } \\
\text { Scale }\end{array}$} & $\begin{array}{l}\text { Negative } \\
\text { Cognitions } \\
\text { About Self } \\
\text { Scale }\end{array}$ & $\begin{array}{l}\text { About the } \\
\text { World Scale }\end{array}$ & Total Score \\
\hline Emotional Pain & $11.5^{\mathrm{a}}(6.7)$ & $50.8^{\mathrm{a}, \mathrm{b}}(22.8)$ & $28.5^{\mathrm{a}}(10.6)$ & $100.5^{\mathrm{a}, \mathrm{b}}(35.7)$ \\
Physical Pain & $12.0^{\mathrm{a}}(6.5)$ & $42.8^{\mathrm{a}, \mathrm{c}}(22.8)$ & $23.9^{\mathrm{b}}(9.5)$ & $86.6^{\mathrm{a}}(37.4)$ \\
Trauma & $11.9^{\mathrm{a}}(7.6)$ & $46.4^{\mathrm{a}, \mathrm{c}}(24.0)$ & $26.9^{\mathrm{a}, \mathrm{b}}(9.6)$ & $95.2^{\mathrm{a}}(37.2)$ \\
Depression & $14.2^{\mathrm{a}, \mathrm{b}}(8.1)$ & $56.5^{\mathrm{b}}(26.4)$ & $29.7^{\mathrm{a}}(10.4)$ & $110.6^{\mathrm{b}}(41.3)$ \\
Joy & $16.1^{\mathrm{b}}(5.7)$ & $40.4^{\mathrm{c}}(19.3)$ & $24.1^{\mathrm{b}}(10.0)$ & $88.4^{\mathrm{a}}(31.4)$ \\
\hline
\end{tabular}

Note. PTCI = Posttraumatic Cognitions Inventory. In each column, means that do not share a common superscript differ significantly at $p<0.05$. 
Table 8.

Means (and Standard Deviations) Across Groups and Rating Categories

Groups (vignettes)

\begin{tabular}{llllll}
\hline & $\begin{array}{l}\text { Emotional } \\
\text { Pain Rating }\end{array}$ & $\begin{array}{l}\text { Physical } \\
\text { Pain Rating }\end{array}$ & $\begin{array}{l}\text { Trauma } \\
\text { Rating }\end{array}$ & $\begin{array}{l}\text { Depression Joy } \\
\text { Rating }\end{array}$ & \begin{tabular}{l} 
Rating \\
\hline Emotional Pain
\end{tabular} \\
\hline & $52.9(30.3)^{\mathrm{a}}$ & $1.1(7.1)^{\mathrm{c}}$ & $9.0(22.6)^{\mathrm{b}}$ & $37.1(30.9)^{\mathrm{a}} 0.0(0.0)^{\mathrm{c}}$ \\
Physical Pain & $8.0(18.2)^{\mathrm{b}}$ & $83.2(28.5)^{\mathrm{a}}$ & $3.3(8.9)^{\mathrm{b}}$ & $5.5(17.5)^{\mathrm{b}}$ & $0.0(0.0)^{\mathrm{c}}$ \\
Trauma & $38.8(33.8)^{\mathrm{a}}$ & $0.1(0.7)^{\mathrm{c}}$ & $40.8(38.0)^{\mathrm{a}}$ & $19.4(27.2)^{\mathrm{b}}$ & $1.0(7.1)^{\mathrm{c}}$ \\
Depression & $39.2(31.3)^{\mathrm{a}}$ & $0.0(0.0)^{\mathrm{c}}$ & $4.8(13.1)^{\mathrm{b}}$ & $55.9(33.6)^{\mathrm{a}}$ & $0.0(0.0)^{\mathrm{c}}$ \\
Joy & $0.2(0.8)^{\mathrm{b}}$ & $0.1(0.7)^{\mathrm{b}}$ & $0.7(4.9)^{\mathrm{b}}$ & $0.0(0.0)^{\mathrm{b}}$ & $99.1(5.7)^{\mathrm{a}}$ \\
\hline
\end{tabular}

Note. In each column, means that do not share a common superscript differ significantly at $p<0.05$. 
Table 9.

Means (and Standard Deviations) for the Number of Words Typed for the Vignette Across Groups

\begin{tabular}{ll} 
Group & Word Count \\
\hline Emotional Pain & $136.9(107.8)^{\mathrm{b}}$ \\
Physical Pain & $105.2(91.1)^{\mathrm{c}}$ \\
Trauma & $192.2(170.1)^{\mathrm{a}}$ \\
Depression & $137.8(121.8)^{\mathrm{b}}$ \\
Joy & $154.3(96.1)^{\mathrm{a}, \mathrm{b}}$ \\
\hline
\end{tabular}

Note. SF-MPQ = Short-Form McGill Pain Questionnaire. In each column, means that do not share a common superscript differ significantly at $p<0.05$. 
Table 10.

\section{Content of Emotional Pain Group Vignettes}

\begin{tabular}{|c|c|c|}
\hline Category & Frequency & Percen \\
\hline All Categories & $n=50$ & $100 \%$ \\
\hline death of a grandparent & $n=12$ & $24 \%$ \\
\hline breakup of romantic relationship & $n=12$ & $24 \%$ \\
\hline death of family member other than grandparent & $n=5$ & $10 \%$ \\
\hline death of friend & $n=4$ & $8 \%$ \\
\hline parent's divorce & $n=3$ & $6 \%$ \\
\hline physical/emotional abuse from parent & $n=3$ & $6 \%$ \\
\hline loved one in life threatening accident & $n=2$ & $4 \%$ \\
\hline estrangement/separation from family & $n=2$ & $4 \%$ \\
\hline property destroyed without insurance compensation & $n=2$ & $4 \%$ \\
\hline questioning religious beliefs & $n=1$ & $2 \%$ \\
\hline family member "comes out" as homosexual & $n=1$ & $2 \%$ \\
\hline diagnosis of life-threatening illness in loved one & $n=1$ & $2 \%$ \\
\hline stress leading to physical illness & $n=1$ & $2 \%$ \\
\hline estrangement/separation from social group & $n=1$ & $2 \%$ \\
\hline
\end{tabular}


Table 11.

Content of Physical Pain Group Vignettes

\begin{tabular}{llc}
\hline Category & Frequency & Percent \\
\hline All Categories & $n=50$ & $100 \%$ \\
sports- related injury & $n=26$ & $52 \%$ \\
injury from falling & $n=4$ & $8 \%$ \\
pain from social loss/rejection & $n=4$ & $8 \%$ \\
pain from infection & $n=4$ & $8 \%$ \\
injury from fighting & $n=3$ & $6 \%$ \\
injury from accident & $n=2$ & $4 \%$ \\
pain from temporary illness & $n=2$ & $4 \%$ \\
chronic pain condition & $n=2$ & $4 \%$ \\
accidently injured by friend & $n=1$ & $2 \%$ \\
pain from labor/birth & $n=1$ & $2 \%$ \\
pain from blood transfusion & $n=1$ & $2 \%$ \\
\hline
\end{tabular}




\section{Table 12.}

\section{Content of Trauma Group Vignettes}

\begin{tabular}{lll}
\hline Category & Frequency & Percent \\
\hline All Categories & $n=50$ & $100 \%$ \\
death of family member other than grandparent & $n=9$ & $18 \%$ \\
loved one in life threatening accident & $n=8$ & $16 \%$ \\
experience of life threatening situation & $n=7$ & $14 \%$ \\
death of friend & $n=5$ & $10 \%$ \\
death of grandparent & $n=4$ & $8 \%$ \\
diagnosis of life threatening illness in loved one & $n=3$ & $6 \%$ \\
rape & $n=3$ & $6 \%$ \\
extreme fear/panic & $n=3$ & $6 \%$ \\
Estrangement from family & $n=2$ & $4 \%$ \\
natural disaster damaged home & $n=1$ & $2 \%$ \\
breakup & $n=1$ & $2 \%$ \\
physical/emotional abuse from parent & $n=1$ & $2 \%$ \\
diagnosed with life threatening illness & $n=1$ & $2 \%$ \\
\hline death of pet & $n=1 \%$ \\
\hline
\end{tabular}




\section{Table 13.}

\section{Content of Depression Group Vignettes}

\begin{tabular}{|c|c|c|}
\hline Category & Frequency & Percent \\
\hline All Categories & $n=50$ & $100 \%$ \\
\hline breakup & $n=15$ & $30 \%$ \\
\hline death of family member other than grandparent & $n=7$ & $14 \%$ \\
\hline Estrangement from social group & $n=5$ & $10 \%$ \\
\hline death of grandparent & $n=4$ & $8 \%$ \\
\hline death of friend & $n=4$ & $8 \%$ \\
\hline physical/emotional abuse from partner & $n=4$ & $8 \%$ \\
\hline rape & $n=3$ & $6 \%$ \\
\hline parent's divorce & $n=2$ & $4 \%$ \\
\hline diagnosis of life threatening illness in loved one & $n=2$ & $4 \%$ \\
\hline Estrangement from family & $n=1$ & $2 \%$ \\
\hline progression of female baldness & $n=1$ & $2 \%$ \\
\hline diagnosed with life threatening illness & $n=1$ & $2 \%$ \\
\hline extreme fear/panic & $n=1$ & $2 \%$ \\
\hline
\end{tabular}




\section{Table 14.}

\section{Content of Joy Group Vignettes}

\begin{tabular}{|c|c|c|}
\hline Category & Frequency & Percent \\
\hline All Categories & $n=50$ & $100 \%$ \\
\hline won sports competition & $n=11$ & $22 \%$ \\
\hline started romantic relationship & $n=8$ & $16 \%$ \\
\hline demonstration of commitment by partner & $n=6$ & $12 \%$ \\
\hline family vacation/ reunion & $n=6$ & $12 \%$ \\
\hline birth of child & $n=4$ & $8 \%$ \\
\hline shared pleasant experience with close friend/ family & $n=4$ & $8 \%$ \\
\hline graduated highschool & $n=3$ & $6 \%$ \\
\hline accepted into organization & $n=3$ & $6 \%$ \\
\hline won non-sports competition & $n=1$ & $2 \%$ \\
\hline received thoughtful gift & $n=1$ & $2 \%$ \\
\hline religious experience & $n=1$ & $2 \%$ \\
\hline aversive presence in life removed & $n=1$ & $2 \%$ \\
\hline bought desired object & $n=1$ & $2 \%$ \\
\hline
\end{tabular}

